\title{
ASPECTOS DE LA CONSTRUCCIÓN DEL CONOCIMIENTO SOBRE LA SOCIEDAD
}

\author{
JuAN DeLVAL ${ }^{1}$ \\ (Recibido el 16/03/2007, aceptado el 25/04/2007)
}

\section{RESUMEN}

El niño tiene que construir modelos o representaciones de la realidad social en la que vive, para tratar de dar un sentido al mundo que le rodea y además esas representaciones sirven de marco para su acción. La mayor parte de esas representaciones mentales no son simples copias de las de los adultos, sino que constituyen una construcción personal y difieren cualitativamente de las de los mayores.

El estudio del desarrollo del conocimiento sobre la sociedad en el niño atrae cada vez más atención por parte de los investigadores. Tres son los enfoques teóricos principales. La posición constructivista, según la cual el niño tiene que realizar su propia construcción de los conocimientos con ayuda de los instrumentos intelectuales de que dispone. La tradición del estudio de las representaciones sociales originada en la sociología francesa y renovada por Moscovici, y la psicología histórico-cultural de tradición vygotskiana. La primera posición pone el acento sobre la actividad del sujeto, mientras que las otra dos enfatizan las influencias ambientales y constituyen un necesario contrapunto de la posición constructivista. Sin embargo, la existencia de creencias infantiles diferentes de las de los adultos y del contexto social, y la universalidad de algunas de estas creencias nos obligan a no olvidar la labor personal de construcción que tiene que realizar el sujeto.

Pero no todos los elementos de esas representaciones tienen la misma naturaleza. Así, mientras que las reglas, los valores y la información fáctica dependen mucho de la influencia del contexto y de la transmisión adulta, en cambio, en las nociones o explicaciones de los procesos sociales (como el intercambio económico o la movilidad social) es donde mejor se pone de manifiesto la labor constructiva del sujeto. Esta distinción ayuda a entender las divergencias entre distintas perspectivas teóricas ya que según los elementos que se estudien se aprecia más claramente la labor de construcción personal del sujeto o la influencia del contexto.

Para ilustrar estos puntos se examinan investigaciones realizadas en diferentes campos y problemas del conocimiento acerca de la sociedad, y en particular acerca de la comprensión de nociones económicas, sobre la estratificación y la movilidad social, sobre el prestigio de las profesiones, sobre los derechos de los niños, o sobre la idea de Dios con sujetos de varias edades.

\footnotetext{
1 Universidad Nacional de Educación a Distancia. Madrid, España.
} 
En el estudio de muchos de los campos del conocimiento social se encuentra que las explicaciones que dan los niños y los adolescentes siguen un orden de progresión semejante, aunque se trate de contenidos distintos, y se encuentran también semejanzas en las explicaciones de los sujetos de diferentes medios sociales y culturales.

Palabras clave: Comprensión infantil de la sociedad, Constructivismo, Representaciones sociales, Nociones económicas.

\begin{abstract}
Childrens must construct models or representations of the social reality in which it lives, to try to give a sense to the world that surrounds to him and in addition those representations serve as frame for their action. Most of those mental representations are not simple copies of those of the adults, but that they constitute a personal construction and they differ qualitatively from those of the greater ones.

The study of the development of the knowledge on the society in the boy attracts attention on the part of the investigators more and more. Three are main the theoretical approaches. The constructivista position, according to which the boy must make his own construction of the knowledge with the help of the intellectual instruments which he has. The tradition of the study of the social representations originated in the sociology French and renewed by Moscovici, and the historical-cultural psychology of vygotskiana tradition. The first position puts the accent on the activity of the subject, whereas the other two emphasize the environmental influences and constitute a necessary counterpoint of the constructivista position. Nevertheless, the existence of infantile beliefs different from those of the adults and the social context, and the universalidad of some of these beliefs forces not to forget the personal work to us construction that it has to make the subject.

But all the elements of those representations do not have the same nature. Thus, whereas the rules, the values and the factual information depend much on the influence of the context and the adult transmission, however, in the slight knowledge or explanations of the social processes (as the economic interchange or social mobility) is where better the constructive work of the subject is shown. This distinction helps to understand the divergences between different theoretical perspective since according to the elements that study it appreciates more clearly the work of personal construction of the subject or the influence of the context.

In order to illustrate these points investigations made in different fields and problems from the knowledge about the society, and in individual about the understanding of economic slight knowledge, on the stratification and social mobility are examined, on the prestige of the professions, the rights of the children, or on the idea of God with subjects of several ages.

In the study of many of the fields of the social knowledge one is that the explanations that give to the children and the adolescents follow an order of similar progression, although it is different contents, and also are similarities in the explanations of the social and cultural means subjects different.
\end{abstract}

Keywords: Children's understanding of society, Constructivism, Social representations, Economic notions.

\title{
EL ESTUDIO DE LAS REPRESENTACIONES DEL MUNDO
}

Durante mucho tiempo la psicología se ha preocupado, sobre todo, por estudiar lo que podemos llamar las funciones psicológicas generales, como la percepción, la cognición, las emociones, las imágenes mentales, el lenguaje, la memoria, etcétera. El enfoque de Piaget 
se centró en estudiar cómo se forman nuevos conocimientos y en la génesis de los mecanismos más básicos que sirven para organizarlos. Su interés era fundamentalmente epistemológico, es decir, referente a cómo se produce el conocimiento y por ello estudió las categorías generales que sirven para organizar la realidad.

Pero una de las principales capacidades que poseen los seres humanos es la de construir representaciones de la realidad que les rodea. El conocimiento del ambiente es una forma esencial de adaptación al medio. La posición constructivista establece que no podemos conocer la realidad tal y como es sino que construimos modelos de ella, la representamos en nuestra mente, lo que nos permite anticipar lo que va a suceder y actuar de acuerdo con esas representaciones.

La utilización de las categorías de espacio, tiempo y causalidad, es decir, de grandes principios organizadores de la realidad, dota a las representaciones de un alcance inusitado. En efecto, los modelos no sólo permiten explicar lo que sucede, dar sentido a los acontecimientos, sino que hacen posible anticipar lo que va a suceder, y ahí radica su importancia. El espacio permite situar lo que sucede en un lugar, la causalidad establecer relaciones de dependencia entre acontecimientos, pero es el tiempo el que posibilita moverse en una dimensión más abstracta, que dota de significado a la causalidad. No es posible desplazarse realmente en el tiempo, pero si puede hacerse mentalmente y predecir lo que va a suceder, para, de esa forma, ajustar la acción actual a lo que se desea obtener. Disponer de esa prodigiosa capacidad de recordar lo que ha sucedido y, por tanto poder extraer enseñanzas hacia el presente y el futuro de lo que ya pasó, y sobre todo de anticipar lo que todavía no ha tenido lugar constituye el gran éxito del hombre y también su punto más débil. La conciencia de la finitud, el miedo a la muerte, la bondad o maldad de las acciones, depende de esa capacidad para representarse lo que va a suceder.

El estudio de las categorías que nos permiten organizar el conocimiento ha constituido un paso muy importante para entender la mente humana, pero es un estudio que queda muy alejado de lo que la gente piensa y hace en la vida cotidiana. Lo que podemos inferir de la observación más elemental es que cuando un sujeto tiene que resolver un problema o dar una explicación lo hace a partir de la construcción de un modelo de ella. ¿Cómo repartir una tarta redonda entre seis personas? ¿Cómo calentar leche evitando que hierva y se nos derrame? ¿Cómo conseguir que todos los niños vayan a la escuela? ¿Cómo hacer que no haya pobres? ¿Cómo reducir el calentamiento global de nuestro planeta?

Del mismo modo podemos observar que nos movemos perfectamente por nuestra casa, incluso a oscuras, porque tenemos una representación de cómo es, vamos al cine y sabemos lo que tenemos que hacer porque tenemos una representación del cine. Por eso resulta muy importante conocer cuáles son esas representaciones y cómo se forman.

Podemos decir pues que hay tres enfoques de la construcción del conocimiento:

1. Un primer enfoque lo constituye el estudio de las grandes categorías que permiten organizar el conocimiento, los grandes mecanismos necesarios para conocer. Es lo que se ha denominado la macrogénesis.

2. Un segundo tipo de estudio lo constituyen los caminos que sigue el sujeto en la resolución de tareas concretas cuando aplica esas grandes estructuras en una situación determinada. Es lo que Inhelder y sus colaboradaras han denominado la microgénesis.

3. Pero cabe estudiar también las representaciones que el sujeto elabora de grandes o pequeñas parcelas de la realidad. 
Podría señalarse que queda un cuarto tipo de estudio que sería el de la conducta que efectivamente realizan los individuos. Pero este tipo de estudio no puede hacerse independientemente y necesita de los anteriores. La conducta directamente observable es demasiado ambigua y puede estar determinada por diferentes estados mentales. Cuando un individuo realiza acciones tan simples como sentarse, ponerse a caminar o golpear a otra persona, no podemos saber por qué lo hace ni qué significado tiene si no tratamos de penetrar en su mente, en sus representaciones de la situación en la que se encuentra.

La construcción de representaciones precisas de la realidad, incluyendo en ella a uno mismo y a los otros, es, sin duda, el mayor logro de la especie humana, su arma más poderosa para controlar la naturaleza. El hombre reconstruye en su mente la realidad, descubre las relaciones entre las cosas, los hechos, traza modelos del funcionamiento de las fuerzas de la naturaleza, de las relaciones físicas entre los objetos, del papel de los otros y de él mismo. Los hombres no se limitan a actuar para satisfacer sus necesidades biológicas, que son irrenunciables e inaplazables, sino que con su mente elabora esos modelos en los que está representado el mundo, lo cual da un sentido más amplio a su actividad y la dota de una eficacia mucho mayor que si se limitara a la pura acción.

Gracias a disponer de sus complejas representaciones o modelos de la realidad el hombre no necesita actuar continuamente para conocer el resultado de sus acciones. A partir de la representación, puede anticipar los resultados de su acción, sin necesidad de experimentar lo que va a suceder: puede predecirlo a partir de las características de su modelo del fenómeno o la situación de la que se esté ocupando. Esto le da un enorme poder sobre las cosas y sobre los otros seres vivos. Actuar mentalmente en el marco de una representación es mucho más rápido y más flexible que actuar sobre las cosas. Disponiendo de un buen modelo se puede experimentar de forma más eficaz que si fuera preciso hacerlo de forma material, pues mentalmente pueden manejarse muchas más posibilidades y de forma más completa. Después de haber experimentado mentalmente es cuando puede realizarse el contraste con la realidad, que en todo caso es la última piedra de toque de las predicciones mentales. El lenguaje y la capacidad de utilización de sistemas abstractos de representación aumentan enormemente las posibilidades de actuar mentalmente, pero no es la causa, sino sólo el vehículo en el que expresar esas representaciones.

El hombre construye representaciones de toda la realidad que le rodea, del funcionamiento de las fuerzas de la naturaleza, de los otros seres vivos y de él mismo. Entre esas representaciones están las de la propia vida social, que incluyen cómo nos relacionamos con los demás, cuál debe ser nuestro comportamiento hacia ellos y qué es lo que esperamos que los demás hagan en las distintas situaciones sociales. El hombre tiene que elaborar entonces modelos del funcionamiento social, de las instituciones en cuyo marco se desarrolla la vida social. Es una labor que tiene que hacer cada individuo, con la ayuda de los otros, basándose en el conocimiento acumulado por las generaciones que le han antecedido, pero que no puede recibir ya hecho. Es, por tanto, una labor psicológica, que se realiza en un ámbito social.

A lo largo de su desarrollo, los individuos llegan a tener ideas bastante precisas sobre cómo funciona el mundo social, sobre las relaciones con los otros y sobre cómo están organizadas las instituciones sociales dentro de las que se desenvuelven. Para actuar en la sociedad, las personas necesitan adquirir ideas acerca de cómo se produce el proceso de compra-venta y cómo está organizada la sociedad desde el punto de vista económico, para qué sirve el dinero y cuál es su valor; y también entienden la organización política, las relaciones de poder, las formas de gobierno, el funcionamiento de la administración. Pero su conocimiento 
no se limita a esto, entienden las diferencias de clases sociales, de razas, de países, la función de instituciones como la escuela, la familia, la nación, la religión, los conflictos entre grupos, que dan lugar a las guerras. Y además entienden las relaciones con los otros, las normas que regulan esas relaciones, la conducta que se debe seguir y la que se debe evitar. En definitiva, se forman 'representaciones' o 'modelos' sobre cómo está organizada y cómo funciona la sociedad, pero también de lo que se debe hacer en distintas situaciones.

Cuando los seres humanos nacen no disponen de esas ideas que sí tienen los adultos, por lo que hay que suponer que las van formando o adquiriendo de alguna manera a lo largo de su periodo de desarrollo y durante el resto de su vida. Lo que tenemos que examinar es cómo se forman, cómo se 'construyen', las ideas sobre el mundo social, sobre las instituciones y sobre las normas que las regulan. Ese es un problema que compete estudiar a la psicología, aunque hay que tener datos de las disciplinas que tienen por objeto estudiar esos distintos aspectos del conocimiento social, tales como la sociología, antropología, economía, ciencia política. Pero estudiar cómo se forman esas ideas no es un mero entretenimiento o una curiosidad, pues las representaciones del mundo social determinan lo que los sujetos hacen y pueden hacer, cómo actúan. Y para entender las concepciones de los adultos, es esencial conocer su proceso de formación. Estamos convencidos, por tanto, de que estudiar la génesis de los conceptos sociales tiene una enorme utilidad para entender las ideas adultas sobre la sociedad y que es un requisito indispensable para desarrollar una epistemología genética de las ciencias sociales. En consecuencia podemos decir que el interés del estudio de la formación del conocimiento social es múltiple y puede considerarse desde el punto de vista epistemológico, desde el psicológico o desde el educativo. Para la educación resulta esencial, pues lo que se pretende en la escuela es que los sujetos formen representaciones adecuadas del mundo en que viven por lo que el profesor tiene que partir necesariamente de las ideas que tienen los sujetos si quiere realizar su tarea de un modo satisfactorio.

Las representaciones no tienen sólo una función explicativa, sino que tratan de satisfacer otras necesidades del sujeto, necesidades que no son sólo de tipo cognitivo, sino que contienen aspectos ideológicos, motivacionales o afectivos. La función explicativa se produce para poder alcanzar los fines de la acción, para poder actuar, por lo que las representaciones están indisolublemente ligadas a los fines que se plantea el sujeto, aunque también los determinan, es decir los sujetos persiguen fines en función de las representaciones que tienen, al mismo tiempo que establecen las representaciones para alcanzar sus fines. Se establece así una relación circular.

Uno de los problemas del estudio de las representaciones es que no puede llegarse a ellas directamente, sino sólo de una forma indirecta, infiriendo a partir de lo que hacen o de lo que dicen los sujetos. Podemos considerar las representaciones como el conjunto de propiedades que los individuos atribuyen a una parcela de la realidad, lo que incluye las propiedades de los elementos, las relaciones entre ellos, las explicaciones de por qué acontecen, las relaciones causales, y otras muchas cosas. Además hay que tener en cuenta que las representaciones se establecen para actuar.

Probablemente las representaciones no están completamente listas y disponibles, elaboradas con todas sus partes, en cualquier momento. El sujeto, en el momento en que lo precisa, combina distintos elementos de los que dispone anteriormente de acuerdo con las necesidades del momento, con los fines que persigue. Parecería pues que los elementos están ya ahí, pero el ensamblaje preciso de ellos sólo se realiza para responder a una necesidad que se produce en un momento determinado. Esa necesidad puede ser de muy diferentes tipos: 
puede ser una necesidad de tipo material, para resolver un problema práctico (cómo conseguir ser admitido en un doctorado), o puede ser para explicar un fenómeno que acontece (por ejemplo, por qué quiere separarse mi mujer de mí, o porque está bajando la cotización de las empresas de nuevas tecnologías en la bolsa). Para entender esos fenómenos, necesito recurrir a las representaciones que tengo, y para ello tengo que elaborar con los elementos de los que ya dispongo una representación adecuada al problema.

Pero lo que me parece cierto es que esas representaciones existen porque las acciones y las explicaciones de los sujetos tienen un carácter bastante unitario, y guardan puntos en común cuando un mismo sujeto trata de explicar diferentes parcelas de la realidad. Esto me lleva a pensar que el conocimiento no está codificado como elementos aislados, sino como bloques más amplios, y que, por tanto, las representaciones existen. Lo que sucede es que una acción no tiene necesariamente que provocar la puesta en marcha de la representación, más que en el caso de que existan elementos discordantes. Cuando voy a encender la luz de mi cuarto no necesito poner en funcionamiento una representación explícita si la luz se enciende al apretar el interruptor, más bien me limito a aplicar un esquema que está automatizado, pero si la luz no se enciende entonces es cuando necesito activar una representación.

\section{Características de las representaciones}

\begin{tabular}{ll}
\hline Origen & Los sujetos precisan de representaciones para sobrevivir en el mundo. \\
\hline Funciones & Las representaciones permiten actuar y entender. \\
\hline Elaboración & $\begin{array}{l}\text { Se producen como respuesta a la satisfacción de las necesidades. } \\
\text { Por tanto, tiene su finalidad en la acción y la supervivencia. }\end{array}$ \\
\hline $\begin{array}{l}\text { Constituyen el contenido de } \\
\text { la mente }\end{array}$ & $\begin{array}{l}\text { Las representaciones son lo que está en la mente de los individuos, son el dato } \\
\text { de que debemos estudiar primordialmente. Pero no son accesibles de forma } \\
\text { directa. }\end{array}$ \\
\hline No son explícitas & $\begin{array}{l}\text { Las representaciones no existen de una forma fijada, más que en casos excep- } \\
\text { cionales, pues se va generando a medida que el sujeto las necesita. }\end{array}$ \\
\hline Características comunes & $\begin{array}{l}\text { Pero las representaciones no son específicas de cada problema, sino que tie- } \\
\text { nen unas características comunes y generales entre ellas, que se muestra so- } \\
\text { bre todo en el tipo de actuación que realizan los sujetos. }\end{array}$ \\
\hline Evolución & La formación de representaciones sigue una serie de estadios regulares. \\
\hline Importancia educativa & $\begin{array}{l}\text { Las representaciones tienen una enorme importancia desde el punto de vista } \\
\text { educativo pues es lo que los profesores tienen que contribuir a formar. }\end{array}$ \\
\hline
\end{tabular}

En todo caso, lo que estamos planteando es que uno de los enfoques de la psicología es estudiar las representaciones, su creación, su desarrollo, y sus tipos.

\section{El mundo social}

Si todavía nos queda mucho por conocer acerca de como son las representaciones de los fenómenos físicos, matemáticos, biológicos o químicos, sabemos todavía menos sobre el mundo social. En ese terreno las cosas son mucho más complicadas. Mientras todos pensamos que nuestra representación de la realidad natural es más o menos adecuada, y que nos aproximamos lentamente hacia una verdad que está ahí, independiente de nosotros, en cambio, en el caso del conocimiento de la sociedad es más fácil darse cuenta de que ese conocimiento está orientado por nuestros prejuicios, por nuestros intereses, por nuestros 
sesgos particulares, por nuestro propio punto de vista, en una palabra, por nuestra posición en el mundo social, como ya había mostrado Marx. El ser rico o ser pobre, poderoso o insignificante, pertenecer a un país o a otro, profesar una religión concreta o no practicar ninguna, ser hombre o mujer, joven o viejo, etc., determina de una manera muy profunda cómo vemos la sociedad y los fenómenos que se producen en ella. Ni tan siquiera las ciencias sociales están al margen de esos sesgos y ésta es una de las causas de la existencia de puntos de vista a veces contrapuestos entre los propios científicos sociales.

Esto añade una dificultad suplementaria a la comprensión del conocimiento sobre la sociedad, respecto al de los fenómenos físicos, pero al mismo tiempo hace especialmente interesante estudiar su génesis. No se trata sólo de un problema de conocimientos escolares, sino que lo importante es ver cómo un individuo se hace adulto dentro de una sociedad determinada y va adquiriendo la ideología de esa sociedad; y también cómo va entendiendo las instituciones sociales, las reglas de funcionamiento social, etc.

Cuando preguntamos a los niños sobre problemas de tipo social, aunque sea incidentalmente en conversaciones informales, nos damos cuenta de la dificultad que tienen para entender cosas que a los adultos nos resultan obvias. Nuevamente, como en el caso del conocimiento acerca de la naturaleza, las respuestas de los niños no son simples curiosidades, sino, como nos enseñó Piaget, la expresión profunda de su pensamiento. Pero estudiar estas cuestiones es más difícil que estudiar las nociones de la ciencia natural, entre otras cosas porque no tenemos una guía tan firme y segura que nos sirva de punto de referencia. Los conceptos de las ciencias sociales no sólo son muy complejos y a menudo están mal definidos, sino que ni siquiera existe un acuerdo sobre muchos de ellos. No todo el mundo coincide en qué es una nación, qué es la plusvalía, qué debemos considerar terrorismo, qué es un sistema democrático o una dictadura, qué es una clase social, por poner sólo unos pocos ejemplos. En todo caso, no son conceptos de precisión comparable a los de masa, cantidad de movimiento o conjunto, sobre los que caben pocas divergencias.

Esta dificultad explica que hasta hace menos de treinta años se habían realizado pocas investigaciones sobre este tema (ver una breve revisión histórica en Delval, 1989 y una revisión por temas en Furnham y Stacey, 1991 y una visión de conjunto de distintos problemas en Barrett y Buchanan-Barrow, 2005), aunque naturalmente hay trabajos pioneros entre los que destacan los estudios de Piaget sobre el juicio moral (1932) y sobre algunas nociones sociales en relación con problemas lógicos (Piaget, 1924).

Hacia finales de los años 60 y principios de los 70 empezó a surgir un nuevo interés por investigar estos problemas al descubrirse la importancia que tenía para el niño conocer los procesos sociales. La razón del escaso interés que se había manifestado durante años, sobre todo dentro de la psicología anglosajona, puede explicarse por el influjo de la posición conductista, que prestaba poca atención a la organización del conocimiento y, además, tendía a creer que la conducta del individuo era, sobre todo, un reflejo del ambiente en el que se desarrollaba. Por ello las investigaciones hasta los años 70 se centraron en el origen de las conductas sociales, en el moldeamiento de la conducta social, dentro de la línea de trabajos como los de Sears o Bandura, pero no en el conocimiento social.

El desarrollo de la psicología cognitiva puso de manifiesto la insuficiencia de los análisis que se limitaban exclusivamente a la conducta, así como la necesidad de estudiar el conocimiento como un aspecto indisociable y determinante de aquella. Algunos psicólogos, influidos por la psicología de Piaget, señalaron que para el desarrollo social del niño era 
esencial que formara representaciones de los otros y de sí mismo, así como de distintos tipos de relaciones sociales: amistad, autoridad, dependencia, etc. Cuando nos dirigimos a otro tenemos expectativas sobre lo que va a hacer, realizamos anticipaciones de su conducta, y la nuestra está guiada por esas anticipaciones. Construimos modelos de las situaciones y nos comportamos adecuadamente dentro de ellas. No es lo mismo que estemos en la puerta del cine y tratemos de entrar, que llamemos a la puerta de la casa de un amigo, o que veamos que se acerca un guardia tras haber cometido una infracción de tráfico. Aprendemos a reconocer cada una de esas situaciones y a comportarnos dentro de ellas de acuerdo con los usos sociales del medio en que vivimos.

Estudiando este tipo de problemas surgió de modo muy floreciente el área que se ha denominado «conocimiento social» (social cognition en inglés) y que estudia un ámbito de problemas muy amplio. Brooks-Gunn y Lewis (1978) han dicho que se ocupa del conocimiento de los otros, de uno mismo, y de las relaciones entre uno mismo y los otros. Esto incluiría entonces el conocimiento de los otros en tanto que individuos, con sus deseos, sentimientos, tendencias, etc., así como el conocimiento de nosotros mismos, también como individuos, con nuestros deseos, estados de ánimo, etc.; el conocimiento de las relaciones sociales entre individuos, las relaciones sociales diádicas; las relaciones y el funcionamiento de los grupos sociales más extensos; y finalmente el funcionamiento de las instituciones sociales, tales como las instituciones políticas, la familia, la escuela, las empresas económicas, etc. (Shantz, 1982).

Los estudios que se han realizado se pueden agrupar bajo tres grandes rótulos, como hace Turiel (1979):

A. El conocimiento de los otros y de uno mismo. El sujeto va elaborando un conocimiento de las otras personas y de las relaciones con ellas, y a través de él se va conociendo a sí mismo. Desde el punto de vista del sujeto, se trata más bien de un conocimiento de tipo psicológico, ya que se tienen en cuenta los estados mentales de los otros y se anticipa cómo se van a comportar entre ellos o en relación con el sujeto. Desde el punto de vista de un observador externo, puede verse como social porque implica la relación con otras personas, pero desde el punto de vista del sujeto es un conocimiento psicológico. Este tipo de estudios es lo que ha sido abordado por los autores anglosajones bajo la denominación de social cognition. Se estudian relaciones interpersonales como la amistad o la autoridad. Los estudios sobre la llamada «Teoría de la mente» pueden encuadrarse en este apartado. Los trabajos sobre la «adopción de perspectivas» (role taking) pueden considerarse también como un componente de ese conocimiento.

B. El conocimiento moral y convencional. El sujeto va adquiriendo las reglas o normas que regulan las relaciones con los otros. Las normas morales regulan los aspectos más generales de las relaciones interpersonales, mientras que las normas convencionales se ocupan de regulaciones más particulares propias de cada sociedad, como las formas de saludo y cortesía, las costumbres, etc. Estos estudios se originan en los trabajos de Piaget sobre el juicio moral, desarrollados por Kohlberg y otros. La línea de trabajos sobre la conducta y el razonamiento prosocial pueden incluirse también aquí (Eisenberg, 1989).

C. El conocimiento de las instituciones. Los estudios que hemos situado en A) se ocupan de los otros en tanto que personas individuales, pero no como seres sociales que se hallan inmersos en instituciones sociales y que se comportan desempeñando «papeles». Lo característico de lo propiamente social, que constituye el objeto de estudio propio 
de la sociología, lo constituye el conocimiento de las instituciones, es decir de relaciones entre individuos o grupos que transcienden al individuo (Berger y Luckmann, 1966). Las relaciones con el tendero, el jefe o el representante político no son relaciones personales, como sería el caso de la amistad, sino que son relaciones entre papeles sociales. Lo que más propiamente podemos llamar conocimiento social es ese conocimiento del funcionamiento de la sociedad en sus distintos aspectos, que es un conocimiento de relaciones institucionalizadas (Delval, 1991).

\section{La formación del conocimiento social}

Estos tres tipos de estudios tienen relaciones entre sí, pero también una cierta independencia y siguen tradiciones de investigación distintas. El área del conocimiento de los otros (A) trata de estudiar más que un conocimiento propiamente social un conocimiento de las personas en tanto sujetos que tienen intenciones, deseos, creencias, etc. Por tanto se trata de un conocimiento, sobre todo, de naturaleza psicológica, aunque se le haya llamado social cognition, denominación que no parece muy adecuada.

El estudio del conocimiento propiamente social (C) es el que se refiere a las instituciones, que es quizá el aspecto menos estudiado, y es de este que nos vamos a ocupar aquí. El conocimiento moral (B) se encuentra entre los dos y constituye un aspecto importante de las relaciones con los otros como individuos y del funcionamiento de las instituciones.

Las instituciones sociales tienen una característica particular y es que en ellas los individuos desempeñan funciones (tendero, jefe, comprador, asalariado, alumno, ciudadano, etc.) y no actúan como un simple sujeto psicológico. Además, las instituciones sociales, que son producto de reglas constitutivas (Searle, 1995), lo que hacen es dotar de nuevo significado a fenómenos que ya existen, y además son fruto del acuerdo social (el dinero vale porque todos admitimos que vale) (cf. Delval, 2000)

Cuando se habla de estos temas, es frecuente que se produzca una confusión entre el origen del conocimiento y su contenido. Tenemos que manifestar de forma inequívoca que, en nuestra opinión, todo conocimiento tiene un origen social, que el conocimiento sólo es posible viviendo en sociedad y que compartimos con los otros el conocimiento, tanto el que tiene como objeto el mundo inanimado, como el que se ocupa de los seres vivos en general o de los seres humanos en particular. Por tanto, tiene que quedar claro que todo conocimiento es social en su origen. Pero el conocimiento puede versar sobre la realidad inanimada, sobre los seres vivos o sobre los humanos y sus relaciones. Es decir que aunque sea social en su origen los contenidos sobre los que trata se pueden referir a cualquier parcela de la realidad.

Pero el hecho de que el conocimiento sea social, de que otros lo posean e intenten transmitírnoslo, de que sea compartido, no quiere decir que se adquiera por copia o transmisión verbal de lo que los otros saben. El sujeto que adquiere un conocimiento no se limita a adquirir lo que otro sabe, sino que lo tiene que reconstruir. De otro modo no se podría explicar que las concepciones de la sociedad de sujetos de distintas edades difieran mucho entre ellas y difieran de las de los adultos, y en cambio se parezcan entre sujetos de parecida edad que viven en diferentes países o culturas.

Sin embargo, algunas explicaciones acerca de cómo se forma el conocimiento sobre la sociedad sostienen que se trata de un proceso de socialización, que el conocimiento está en la sociedad y es implantado en el individuo por la presión social. Eso es cierto, pero, desde 
el punto de vista del psicólogo, lo que hay que explicar precisamente es cómo se produce esa interiorización del conocimiento.

Por ejemplo, la teoría de las representaciones sociales propuesta por Moscovici (1976) ha tratado de ocuparse de un tipo de representaciones que serían compartidas por un grupo social de características determinadas. Esas representaciones sociales se adquirirían en la vida social y vendrían hechas del exterior. Como dice Moscovici (1976, p. 66), el individuo forma parte de un 'coro' colectivo, que constituye la opinión pública, en el que el individuo participa, lo quiera o no. Por tanto, el sujeto es un elemento pasivo que se limita a cantar en ese coro la partitura que recibe socialmente.

De forma parecida, la psicología histórico-cultural, inspirada en las ideas de Vygotski, pone también el acento en la adquisición por el individuo de conocimientos que están en la sociedad. Pero de este modo no podemos explicar la originalidad que tienen las concepciones sobre la sociedad que defienden los niños (Delval, 2002).

La concepción de la formación de las representaciones que defendemos es mucho más amplia que la de Moscovici o la de la psicología histórico-cultural y, como veremos, el individuo tiene un papel activo en su elaboración que va mucho más allá de formar parte de un coro o de interiorizar lo que piensan los adultos. Precisamente lo que interesa estudiar son las dificultades que el sujeto encuentra para llegar a las nociones adultas y las etapas por las que pasa.

\section{Los campos de la representación del mundo social}

Después de estas observaciones, sobre cómo se va formando el conocimiento social, vamos a tratar de describir qué temas, aspectos o campos pueden incluirse bajo ese rótulo. La representación del mundo social es algo enormemente amplio y con límites difusos, en donde se pueden distinguir aspectos centrales y aspectos periféricos. Posiblemente los dos problemas centrales de la representación del mundo social son la comprensión del orden político y la comprensión del orden económico, que constituyen una especie de columna vertebral en torno a la que se organizan otras cuestiones. Pero, además de los problemas que podemos considerar genuinamente sociales, hay muchos otros que no lo son estrictamente, pero que tienen una vertiente social clara como la vejez o la muerte. Vamos a enumerar distintos aspectos que forman parte de esa representación del mundo social, que no la agotan, pero que dan una idea de la amplitud de la problemática.

Respecto al funcionamiento económico de la sociedad, es importante averiguar cómo se entiende la producción y el intercambio de las mercancías, y ligado a ello, cuál es el papel del dinero. Esto a su vez está en conexión con la distribución social de la riqueza y la existencia de clases sociales y aquí aparecen entonces los problemas de la comprensión de las diferencias sociales, de la estratificación y la movilidad social.

Respecto a la comprensión del orden político, temas centrales son el papel de los partidos políticos, el funcionamiento del sistema democrático y de otros sistemas políticos, de las instituciones, la representación parlamentaria, el cambio político, la alternancia en el poder, etc. Un aspecto más profundo del problema, es el de la comprensión de las nociones de autoridad y poder y su extensión desde el punto de vista social. Otro aspecto de gran importancia es la comprensión de las leyes, su origen, su función, su evolución, el papel del derecho en la sociedad y las relaciones entre derecho y moral. 
Además de estos dos temas centrales, hay otros muchos aspectos relativos a instituciones o simplemente a fenómenos ligados a la práctica social. Entre estos hay que destacar las ideas referentes a la propia nación, la aparición de un apego hacia el propio país y la comprensión del país como una unidad multidimensional, política, económica, cultural, lingüística, religiosa, geográfica, etc. Muy estrechamente relacionado con esto están las ideas y actitudes hacia otros países, y la aparición de sentimientos negativos como el racismo y la xenofobia.

La concepción de la familia y de su papel dentro de la sociedad, las relaciones de parentesco, las funciones paterna y materna y, en relación con ello, el problema de la adopción de papeles sexuales o de género, constituyen otro de los aspectos importantes de la comprensión de la sociedad. La adopción de papeles sexuales ha sido estudiada tradicionalmente desde la perspectiva de la socialización mientras que se han descuidado los aspectos cognitivos del problema, es decir, cómo perciben los sujetos su papel y el de los individuos que pertenecen a otro sexo.

Ligada a la existencia de clases sociales, que tiene un fundamento económico, aparece la cuestión de la adopción de papeles sociales, la comprensión de las profesiones y todo lo relativo a la división del trabajo, lo cual se conecta con los progresos del niño en la diferenciación entre los individuos y su papel social.

Los niños pasan una gran cantidad del tiempo en la escuela y construyen ideas sobre cuál es la función de ésta y qué es lo que hacen en ella. El problema de la transmisión del saber, de la generación de conocimientos desde el punto de vista social y de la difusión de esos conocimientos, así como el papel de la ciencia como forma de poder, es otro de los aspectos de nuestro tema, pero que ha sido muy escasamente estudiado.

El nacimiento y la muerte, además de fenómenos biológicos, son fenómenos sociales; los jóvenes, los adultos y los viejos tienen un papel en la sociedad, y cada sociedad les otorga un lugar. La visión de las etapas de la vida, desde la infancia hasta la vejez, en relación con la organización social, constituye otra parte del campo que nos ocupa.

La guerra y la paz, así como las relaciones entre las naciones en todos los terrenos, forman un aspecto más de este campo que debe ser estudiado. Los niños se interesan enormemente por la guerra como forma de dominación, pero tienen de ella un conocimiento irreal y esquemático. El paso de esa concepción a las ideas complejas de los adolescentes, que incluyen aspectos políticos, económicos y sociales en la conceptualización de la guerra, es un tema que vale la pena estudiar.

La religión constituye también un fenómeno social y las ideas que el niño tiene en el terreno religioso no coinciden con las de los adultos. Es importante por ello saber cuáles son esas ideas de los niños, cómo conciben a Dios, o aspectos más mundanos, como son su pertenencia a una comunidad religiosa, en una palabra, cómo es la religión del niño.

Por último, un problema central, que aparece ligado a todos los anteriores, es la comprensión del cambio social, cómo evolucionan las sociedades a lo largo de la historia. Este tema está en relación con el del tiempo histórico, algo que resulta incomprensible para el niño durante largos años. Los niños tienden a ver la sociedad de forma estática y el tiempo sólo aparece tardíamente como un elemento relacionado con los fenómenos sociales. Una compresión completa de la sociedad exige entender la evolución histórica de las sociedades. 
Los distintos campos de la representación del mundo social tienen características diferentes y grados de dificultad desigual. En algunos casos se trata simplemente de comprender regulaciones sencillas sobre ciertos usos sociales. En otros hay que entender sistemas simples, muchos de cuyos aspectos pueden comprenderse de una forma concreta. Esto sucede, por ejemplo, con muchas vertientes de la idea de país. En cambio, en otros casos se trata de entender un sistema muy amplio que está formado a su vez por subsistemas que interactúan, como en el caso de la organización económica o la organización política de la sociedad, que resulta muy compleja de entender y su comprensión parece exigir instrumentos de tipo formal.

\section{Aspectos sobre los que versan las representaciones de la sociedad}

\begin{tabular}{|c|c|}
\hline Economía & $\begin{array}{l}\text { Producción e intercambio de mercancías. La ganancia } \\
\text { El dinero } \\
\text { Las fuentes de riqueza. La riqueza de los países } \\
\text { El consumo } \\
\text { El trabajo y el empleo (en relación con la organización social) }\end{array}$ \\
\hline Política & $\begin{array}{l}\text { El poder y la autoridad } \\
\text { Sistema de gobierno } \\
\text { Partidos políticos } \\
\text { Instituciones } \\
\text { Las leyes y la justicia } \\
\text { El conflicto (en relación con la guerra y la paz) }\end{array}$ \\
\hline Nación & $\begin{array}{l}\text { El conocimiento del propio país } \\
\text { Los extranjeros } \\
\text { Los símbolos nacionales } \\
\text { El sentimiento nacional }\end{array}$ \\
\hline Familia & $\begin{array}{l}\text { La concepción de la familia } \\
\text { Papeles sexuales }\end{array}$ \\
\hline Diversidad social & $\begin{array}{l}\text { Diferencias de raza } \\
\text { Prejuicio }\end{array}$ \\
\hline Organización social & $\begin{array}{l}\text { Estratificación social. Ricos y pobres } \\
\text { Movilidad social. Cambios de nivel } \\
\text { Clases sociales } \\
\text { Las profesiones }\end{array}$ \\
\hline Guerra y paz & $\begin{array}{l}\text { El conflicto social } \\
\text { La guerra, sus causas y sus soluciones }\end{array}$ \\
\hline Nacimiento y muerte & $\begin{array}{l}\text { La reproducción biológica de la sociedad } \\
\text { Los rituales sociales } \\
\text { La socialización del niño } \\
\text { La muerte como fenómeno social }\end{array}$ \\
\hline Religión & $\begin{array}{l}\text { El sentido de la vida } \\
\text { La creación del mundo } \\
\text { La religión } \\
\text { El dios de los niños } \\
\text { El más allá }\end{array}$ \\
\hline La escuela y el conocimiento & $\begin{array}{l}\text { La necesidad de la escuela } \\
\text { La escuela como institución } \\
\text { La transmisión social del conocimiento. La ciencia }\end{array}$ \\
\hline La historia & $\begin{array}{l}\text { El cambio de las sociedades } \\
\text { El tiempo histórico }\end{array}$ \\
\hline
\end{tabular}


Cada uno de los distintos campos requiere el empleo de los instrumentos intelectuales que el niño forma a través de su acción sobre el mundo y uno de los problemas de interés en este estudio es ver cómo interactúan los medios intelectuales del sujeto con los conceptos sociales que forma y si esa interacción es del mismo tipo que la que se produce respecto a los conceptos físicos o matemáticos.

Como no podemos examinar con un mínimo de detalle cómo van progresando las ideas de los niños en los campos que hemos mencionado anteriormente (véase una revisión más extensa en Delval, 1989 o Furnham y Stacey, 1991; sobre nociones económicas Berti y Bombi, 1981/88; ver también Furth, 1980; Delval, Enesco y Navarro, 1994), vamos a limitarnos a tratar brevemente como ejemplos las ideas sobre un concepto económico (la ganancia), sobre la estratificación social, el trabajo y las profesiones, y sobre los derechos de los niños y sobre la idea de dios.

\section{De qué están hechos los modelos sociales}

Las representaciones sobre el mundo social tienen algunas características peculiares que las diferencian de otras representaciones, debido al carácter propio del conocimiento social. Es especialmente importante el papel que las normas y los valores desempeñan en la vida social. Las normas sociales regulan la vida social, pero, a diferencia de las reglas de la naturaleza, pueden respetarse o no respetarse (Delval y Enesco, 1994).

Puesto que el hombre es un ser social que sólo puede desarrollarse dentro de una sociedad y en contacto estrecho con los otros, los adultos tratan de que los niños se conviertan en miembros completos de esa sociedad, inculcándoles las normas, valores, actitudes y formas de comportamiento que caracterizan a los miembros de esa sociedad, en un proceso que globalmente se suele llamar socialización, y que no presupone necesariamente cómo se produce, si mediante la presión de los otros o a través de la actividad constructiva del propio sujeto.

Una de las primeras cosas que los sujetos adquieren son las normas o reglas sobre lo que debe hacerse y sobre lo que no debe hacerse. Los adultos se cuidan mucho de que la conducta de los niños siga esas normas y ponen un gran empeño en ello, pues esto es lo que va a garantizar que en el futuro su conducta pueda considerarse social, y que el sujeto pueda interaccionar con los otros. Por ello desde muy pronto se les anima o se les reprime para que se comporten de acuerdo con lo que se considera adecuado. Esas normas están estrechamente ligadas a valores sociales que indican lo que es deseable y lo que no lo es desde el punto de vista de los otros. Esos elementos prescriben lo que debe hacerse y se refieren a cómo deben ser las acciones, no a cómo son. Normas y valores son constituyentes esenciales del conocimiento y de la conducta social.

Pero el niño recibe además informaciones sobre muchos hechos sociales, sobre aspectos concretos de la realidad social, y también las obtiene él mismo actuando dentro del mundo social, registrando sus regularidades y reflexionando sobre él.

Junto con todo lo anterior, y apoyándose en ello, va elaborando explicaciones sobre cómo y por qué suceden las cosas de una determinada manera, en definitiva, sobre el funcionamiento de los sistemas sociales.

Normas, valores, informaciones y explicaciones son entonces algunos de los elementos que componen los modelos o representaciones que el niño va elaborando sobre el mundo social, 
elementos que podemos agrupar en tres tipos: normativo-valorativos, informativos y explicativos. Quizá esta distinción pueda parecer trivial, pero no tenerla presente da lugar a muchos equívocos en las investigaciones y, sobre todo, en lo referente a cómo se produce el conocimiento social. Intentaremos explicar por qué.

Las normas y los valores que prescriben lo que se debe hacer se empiezan a adquirir desde muy pronto y los adultos ponen un particular empeño en que los niños los adquieran. («No pegues a los otros niños», «para comprar en la tienda hay que llevar dinero», «tienes que ir a la escuela para aprender», serían ejemplos de ello.) Por lo tanto, se transmiten explícitamente y se estimula su imitación, de tal manera que su labor mental en los comienzos de la adquisición de las normas es relativamente pasiva ya que los sujetos las reciben en gran medida hechas. En este caso la transmisión directa por parte de los adultos desempeña un papel importante y podría pensarse que el niño se limita a incorporar lo que los adultos le transmiten, pero, de todas formas, el niño sólo es capaz de incorporar aquellas normas que están al alcance de su comprensión.

En muchos casos, las informaciones las recibe también directamente de los adultos o de los medios de comunicación y además la escuela dedica una importante parte de su actividad a la transmisión de informaciones, aunque también el niño las busca por sí mismo. (Ejemplos de estas serían: «Brasilia es la capital de Brasil», «Benito Juárez fue presidente de México», «médico es una profesión prestigiosa», «la bandera colombiana es blanca, azul y roja».)

\section{Elementos de las representaciones sociales}

\begin{tabular}{|c|c|c|}
\hline \multicolumn{3}{|c|}{$\begin{array}{l}\text { Los modelos que el sujeto construye de la realidad están formados por distintos tipos de elementos de diferente } \\
\text { naturaleza, que difieren en cómo son transmitidos. }\end{array}$} \\
\hline Reglas o normas & $\begin{array}{l}\text { Indican cómo se debe uno comportar } \\
\text { en las diferentes situaciones sociales }\end{array}$ & $\begin{array}{l}\text { Se adquieren pronto por la influencia exterior. El } \\
\text { niño las conoce antes de saber para qué sirven } \\
\text { o por qué se deben cumplir. } \\
\text { Cobran un sentido diferente cuando se constru- } \\
\text { yen explicaciones de la sociedad. }\end{array}$ \\
\hline Valores & $\begin{array}{l}\text { Expresan lo que la sociedad conside- } \\
\text { ra positivo o negativo, lo que debe } \\
\text { hacerse o no. Están muy ligados a } \\
\text { las normas }\end{array}$ & $\begin{array}{l}\text { Se adquieren pronto mediante transmisión de } \\
\text { adultos o compañeros. El sujeto trata de adaptar } \\
\text { sus valores a los de sus compañeros y los com- } \\
\text { parte con ellos. }\end{array}$ \\
\hline Informaciones & $\begin{array}{l}\text { Conocimientos sobre aspectos con- } \\
\text { cretos de la realidad social }\end{array}$ & $\begin{array}{l}\text { El sujeto las recibe del ambiente, por transmisión } \\
\text { de los adultos, de los medios de comunicación y } \\
\text { de la escuela. }\end{array}$ \\
\hline $\begin{array}{l}\text { Nociones } 0 \\
\text { explicaciones }\end{array}$ & $\begin{array}{l}\text { Permiten la comprensión de un as- } \\
\text { pecto de la realidad social }\end{array}$ & $\begin{array}{l}\text { Se adquieren más tarde que las reglas y valores } \\
\text { y suponen un largo trabajo constructivo de ela- } \\
\text { boración personal por parte del sujeto. Una vez } \\
\text { construidas sirven para explicar y justificar nor- } \\
\text { mas y valores establecidos anteriormente. }\end{array}$ \\
\hline
\end{tabular}

Por el contrario, las explicaciones sobre por qué son así las cosas, sobre cómo funcionan los sistemas sociales, y los conceptos en que se apoyan, apenas se enseñan. No se le explica al niño el sistema de la tienda y la distribución de mercancías, ni sus relaciones con el proceso de producción. Ni tampoco se le explica cómo se produce la movilidad social y 
cuáles son sus determinantes, ni las causas que motivan las guerras. Y cuando se le enseñan esas cosas, hace ya mucho tiempo que tiene explicaciones para ellas, explicaciones que ha tenido que construir por sí mismo, porque nadie se las ha dado, y que suponen un trabajo de elaboración propio. El niño las construye con los instrumentos intelectuales de que dispone y llega a explicaciones que no coinciden con las de los adultos y que curiosamente son muy semejantes entre niños de distintos medios sociales y de diferentes países, aunque pudiera creerse lo contrario.

Así vemos que el niño aprende muy pronto como una regla que para comprar hay que llevar dinero a la tienda, mucho antes de que sea capaz de explicar para qué sirve ese dinero, qué hace el tendero con él, cómo se fijan los precios, y en general cómo tiene lugar la actividad económica. Posteriormente las explicaciones inciden sobre normas y valores y los reorganizan, y cuando se alcanza un grado de comprensión grande, esas explicaciones proporcionan a las normas y valores un sentido nuevo, haciendo posible la reflexión sobre ellos, e incluso dudar de sus fundamentos.

Algo semejante puede decirse de las informaciones. A nuestros niños se les enseña al llegar a la escuela que «Madrid es la capital de España» y todos saben repetirlo sin errores. Pero, como han puesto de manifiesto varias investigaciones (Piaget y Weil, 1951), y nosotros mismos hemos estudiado, antes de los siete años no suelen entender que hay más españoles que madrileños, que no todos los españoles son madrileños, pero si sucede lo contrario, y tampoco tienen la más remota idea de lo que quiere decir «ser capital de» ni lo que es una capital, ni un país (Delval, del Barrio y Echeíta, 1981; Delval, 1989). Así pues, esa información no les sirve de mucho en ese momento, ni pueden integrarla en sus explicaciones de la organización administrativa de un país.

Consideramos que es útil tener presentes las distinciones anteriores porque cuando estudiamos los modelos del mundo social que elaboran los sujetos, si nos interesamos especialmente por su conocimiento de las reglas, valores e informaciones no podemos apreciar plenamente la labor constructiva del sujeto, que en gran medida está reproduciendo lo que se le ha transmitido. Por ello lo que nos dice depende mucho del medio social y de la cultura en la que vive, de las ideas dominantes, aunque también las está asimilando con sus instrumentos intelectuales. En cambio, en las explicaciones sobre el funcionamiento de los sistemas sociales y en los conceptos que forman parte de ellas, las variaciones son menores y encontramos procesos constructivos que son mucho más universales. Es fácilmente comprensible que los contenidos del pensamiento tienen que variar de acuerdo con el entorno, pero la manera de explicar los fenómenos, que está mucho más ligada a las capacidades mentales de los sujetos, es más semejante.

\section{El desarrollo de las nociones económicas}

El problema de cómo entiende el niño la realidad económica y los conceptos referidos al uso del dinero, tiene un enorme interés y puede servir como modelo de la comprensión infantil de la realidad social. Hay al menos dos razones para considerar que se trata de un campo de mayor importancia dentro del estudio del desarrollo psicológico del niño. En primer lugar, por el propio interés del problema: las nociones económicas constituyen un eje de la organización social y además el niño está en contacto con ellas desde muy pronto, posiblemente antes que con otras muchas nociones sociales, como podrían ser las políticas. 
En segundo lugar, por las posibilidades de estudio. En efecto, el campo de lo económico, aun siendo difícil de abordar, como todas las nociones sociales, sin embargo se presta mejor, quizá por su carácter más objetivo, al estudio experimental. Se trata de una realidad con la que el niño, al menos en la sociedad capitalista, entra en contacto desde muy temprano a través de su experiencia diaria, por ejemplo, de ir a la tienda a comprar. Pero además hay elementos fácilmente objetivables, como el problema del cambio en la tienda, o la noción de ganancia que pueden estudiarse de una manera muy directa. Sin embargo, a pesar de esto, hasta hace poco tiempo apenas se le ha prestado atención, y todavía hoy sabemos poco sobre el proceso general y menos sobre los detalles del desarrollo de la comprensión de lo económico. Destacan los trabajos realizados por Strauss y por Danziger en los años 50, y más recientemente por Furth (1980), Jahoda $(1979,1983,1984)$ y Berti y Bombi (1981/88). Estas últimas autoras italianas han estudiado, en una serie de investigaciones recogidas en su libro El mundo económico en el niño, diversos aspectos de su comprensión de lo económico. Nosotros mismos hemos realizado algunos estudios sobre el tema (véase Delval y Echeíta, 1991; Delval, 2001).

La primera realidad económica con la que el niño se relaciona es probablemente la de la tienda. El niño aprende pronto que en la tienda se obtienen cosas y que se obtienen a cambio de dinero. Pero a los cinco años todavía no entiende cómo se produce el cambio. Para el niño el dinero es un elemento ritual que hay que llevar para comprar, pero piensa que muchas veces el tendero devuelve más de lo que se le da, hasta el punto de que, según los niños de 5-6 años, una de las fuentes de dinero es ir a comprar a las tiendas. Otra fuente son los bancos, donde se pide dinero y te lo dan o se saca con una tarjeta.

Dos nuevos problemas relacionados surgen a continuación: qué hace el tendero con el dinero que recibe y de dónde saca las cosas que vende, o dicho en otras palabras, qué hace cuando se le terminan las cosas. Los niños de 6-7 años creen que el tendero guarda el dinero en un cajón y lo utiliza para dar la vuelta. A veces coge también dinero para comprarse algo.

Pronto se dan cuenta, sin embargo, de que las cosas se acaban y el tendero tiene que sustituirlas. Algunos niños creen que al tendero se las dan y no tiene que pagar por ellas, sólo se encarga de venderlas. Pero la mayoría piensa que tiene que pagar por ellas. Señalan que cuando se le acaban los lápices va a otra tienda y compra otro lápiz para venderlo o llama por teléfono para que se lo traigan.

Surge así un problema de gran importancia para la comprensión de los fenómenos económicos: la idea de ganancia. Los niños, hasta los 10-11 años, tienen grandes dificultades para entender que hay una diferencia entre el precio de compra y el precio de venta y que el tendero vende más caro de lo que a él le cuesta. Sorprendentemente los niños piensan que el tendero compra las mercancías en una fábrica (o en otra tienda), y paga por ellas un precio; luego las vende por lo mismo o por menos de lo que le ha costado. Con el dinero que obtiene de esa venta viven él y su familia, paga a sus empleados y repone la mercancía.

\section{La idea de ganancia}

La idea de la ganancia del vendedor, como diferencia entre el precio de compra y el precio de venta, parece extremadamente elemental, y por ello muy simple de entender, y así resulta para los adultos. Pero para los niños darse cuenta de que tiene que haber una diferencia necesaria entre el precio de compra y el precio de venta es algo que resulta 
sorprendentemente complicado de entender, y que sólo se logra años después de que el niño haya empezado a participar en actividades de compra.

Las líneas generales del pensamiento de los niños, hasta los $10 \mathrm{u} 11$ años, puede resumirse de la siguiente manera: El tendero compra las mercancías en una fábrica (o en otra tienda), y paga por ellas un precio; luego las vende por lo mismo o por menos de lo que le han costado. Con el dinero que obtiene de esa venta vive él y su familia, paga a sus empleados y repone la mercancía.

Desde el punto de vista del adulto, esa explicación es imposible, pues implica una multiplicación del dinero, pero no lo es para los niños, pues de una manera más o menos completa, más o menos detallada, adornada con unos u otros detalles, todos lo explican así. Esto nos obliga a suponer que es la más coherente que puede construir con los elementos intelectuales de que disponen, y que así ven la realidad económica que les rodea. En la tabla ofrecemos las respuestas de niños españoles a la pregunta de cuánto paga el tendero al que le proporciona las cosas que vende. Como se ve, hasta los diez años predominan las respuestas en las que se dice que el tendero paga más o igual que el precio de venta.

\section{Cuánto paga el tendero al proveedor (porcentajes)}

\begin{tabular}{cccccc}
\hline Edad & $\mathbf{6}$ años & $\mathbf{7}$ años & $\mathbf{8}$ años & $\mathbf{9}$ años & $\mathbf{1 0}$ años \\
\hline Más & 26 & 49 & 13 & 12 & 4 \\
Igual & 49 & 57 & 64 & 55 & 13 \\
Menos & 9 & 8 & 24 & 47 & 91 \\
\hline
\end{tabular}

Los sujetos más jóvenes piensan que el tendero compra las cosas a un precio mayor o igual que el que luego cobra a los clientes, pero hacia los 10 años la idea dominante es que cobra más para poder ganar. En algunos casos los porcentajes suman más de 100 porque los sujetos responden «igual 0 más» (Basado en Delval y Echeita, 1991).

Si bien se mira el fenómeno no deja de ser curioso porque, a pesar de que los niños están inmersos en una sociedad centrada sobre la ganancia, no consiguen entenderla, e incluso la rechazan. Este es un problema que debe darnos qué pensar, y que sirve para que desechemos posiciones ambientalistas de tipo rudimentario. Si el niño aprendiera a comprender la realidad social simplemente por la presión del ambiente, si sus ideas no tuvieran un fuerte componente de construcción propia, entenderían ideas como la de ganancia mucho antes. Los resultados de investigaciones realizadas en Inglaterra, Holanda, Italia, México, e incluso entre niños vendedores ambulantes, arrojan resultados semejantes, sólo con algunas diferencias en las edades. Las respuestas de estos niños vendedores en la calle son interesantes porque mientras que tienen un mejor conocimiento del proceso de compra-venta en algunos aspectos relacionados con su propia práctica, sin embargo no comprenden mejor el problema de la ganancia en sus aspectos generales (Delval, Díaz-Barriga, Hinojosa y Daza, 1992), lo que nos enseña bastante sobre el papel de la experiencia propia en la formación del conocimiento social.

\section{Ejemplos de respuestas al problema de la ganancia}

\section{No comprensión}

CARLOS (7;4, Madrid) «-¿Qué hace cuando se le terminan [los lápices]? Le han ido dando dinero, con el dinero que tiene va comprando más en otras papelerías, también 
en las fábricas [obsérvese que este sujeto señala, como otros que hemos visto, que el tendero compra en otra tienda igual a la suya]. - ¿Hay que pagar a la fábrica? Sí.-¿Igual, más o menos? Más, porque les ha costado más hacerlo. - ¿De dónde sale el dinero para pagar? De lo que yo te he dado.- ¿Y con qué dinero compra la ropa? De lo que la gente le da.-(...) Entonces, ¿Los tenderos venden por más, por menos o igual que lo que les ha costado a ellos en la fábrica? Lo venden por menos, porque a los de la fábrica les ha costado mucho hacerlo y a él venderlo no».

OsCar $(8 ; 11$, Madrid) «- ¿Lo vende por lo mismo que le ha costado, por más o por menos? Por menos, lo puede poner por más, pero le compensa más por menos, porque si la fábrica pone 25 y lo vende por 50 vende menos, pero si lo vende por 20 venderá más. -Si lo vendo por 20 y me ha costado 25, ¿gano algo? No, bueno sí. Bueno, perderás dinero, pero te compran más. No ahorras más dinero».

Guiomar (10;3, Madrid) «- ¿Sabes lo que son las rebajas? Sí, un precio te vale a 100 pts normal, si está rebajado es que te vale menos. Por ejemplo, este bolígrafo si vale 25 se dice que está rebajado cuando vale menos, 22 pts, por ejemplo. - ¿Tú crees que ganan dinero los señores de las rebajas? Es que las rebajas lo hacen para que la gente vaya a comprar más, entonces también ganan según la gente que vaya a comprar. Si tú compras 10 bolis y si sólo te compran 1 sales perdiendo tú. A lo mejor en las rebajas pagas menos dinero de lo que vale, pero como va más gente también ganas. - Va mucha más gente, pero ¿él sigue ganando dinero con cada cosa que vende? Claro, porque va mucha gente. Si vale 20 una cosa y está rebajada a 15, por ejemplo, aunque esté rebajado, pierde 5 pts, pero como va mucha gente sale ganando. $-i \mathrm{O}$ sea que pierde dinero? No, porque como lo que vale es más de lo que pierde porque va mucha gente ... - O sea que a mí me lo venden a 20 , yo pongo rebajas y lo bajo a 15 pts. Pierdo 5 pts, pero como viene mucha gente a comprar ... ¿es eso lo que dices? Claro».

Paula (9;11, México, D.F.) «¿Cuánto te cuesta un lápiz? 500 pesos. - ¿Y el señor que vende los lápices cuánto tiene que pagar? 1000 pesos, no, 500, igual. - ¿Y por qué igual? Porque se lo compra al de la fábrica. - ¿Y $\mathrm{Y}$ a ti en cuánto te lo vende? En 500. Entonces ¿lo vende igual, por más o por menos de lo que le costó? Igual. - ¿Por qué igual? No sé, yo creo que le han dicho que ese es el precio que está bien. - ¿Y para qué crees tú que usa el señor de la papelería el dinero que recibe? Para mantener a sus hijos, para hacer la comida, para su casa, así, así.»

Bárbara (11, Culiacán, México) «-¿Cuánto te cuesta un lápiz? 500 o 600 pesos. - ¿El señor de la papelería dónde consigue los lápices? En las fábricas. — ¿Tiene que pagar por los lápices? Yo diría que sí. _- ¿Como cuánto tiene que pagar? Como 1000 pesos. ¿Por qué como 1000 pesos? Porque los fabricantes no regalan a las personas lo que fabrican, porque a ellos les cuesta. - El señor de la tienda tiene que comprar a la fábrica, y la fábrica vende a 1000 pesos, ¿a ti a cómo te lo venden? A 600. ¿Gana o no gana? Gana poco, 400 o poco menos. - ¿Podría venderlo el señor de la tienda a 300 pesos? No, porque ya no ganaría nada. - ¿Y lo podría vender a 1000? Ganaría más que a 600. - ¿Cuánto ganaría? 600 o 500 o 700 le saldría mejor al señor de la tienda, venderlo a más, menos o igual de como se lo venden a él? Le saldría mejor que se los vendieran a más. - ¿Pero a menos de lo que le costó? A 600 o a 1000. - ¿De todas maneras gana? No gana mucho, pero gana, como 600. - ¿A los señores de la fábrica les 
cuesta dinero hacer los lápices? Pues sí, toda la maquinaria. - ¿Como cuánto crees que les salga un lápiz? Como a 800 o a 1000.»

\section{Comprensión}

Roвerto (10;7, Madrid) «-Y cuando se me acaban los bolígrafos ¿qué hago? Comprar más de lo que has ganado, con el dinero que has recibido de vender las otras cosas. ¿Y dónde lo voy a comprar? A la fábrica. - ¿Yo le tengo que pagar al de la fábrica? Sí. - ¿Le pago lo mismo que lo que me has pagado tú, o sea 25 pts, más ó menos? El que vende lo pone a más de lo que lo ha comprado él para ganar. - ¿Siempre es así? Sí. Entonces ¿cuánto crees que me ha costado a mi este bolígrafo? Te lo he vendido a ti a 25. A ti te habrá costado, supongo que entre 15 ó 20 , pongamos 15 . - ¿Yo he ganado dinero? Sí, porque pagas 15 y lo vendes a 25 y te llevas 10 pts de más. ¿No ganas 25 ? No, porque tienes que pagar 15 por este boli. - ¿Los señores de las fábricas también ganan dinero? Sí. - ¿Cómo? A las personas de las fábricas les pagan en las fábricas. ¿Cuánto crees que le habrá costado el boli a los de la fábrica, si me lo vende por 15 pts? Menos de 15. - ¿Y eso pasa siempre? Supongo que sí, porque si no tampoco ganas nada».

En el cuadro hemos reproducido literalmente algunas de las respuestas de los niños, que hemos obtenido en una investigación con G. Echeíta y en otra con F. Díaz-Barriga (no publicada) con niños mexicanos (véase Delval y Echeíta, 1991). Se les plantea una situación de una tienda en la que el niño hace de comprador.

Muchos chicos señalan que el tendero puede cobrar lo que quiera por lo que vende, pero en el fondo está bastante determinado porque hay un precio justo al que se debe vender y que sólo se puede modificar en parte. Las cosas no se pueden modificar de precio «porque ya están con el precio pensado», como nos dice una niña de 7 años. Pero al mismo tiempo es conveniente vender barato porque de esa forma se vende más. Esta es una de las razones por las que el tendero vende por menos precio de lo que él ha pagado: así vende más. Y como el niño no es capaz de ver el proceso en su conjunto no le preocupa lo que sucede. En las respuestas se ponen de manifiesto algunos de los problemas que los niños encuentran para entender correctamente el problema de la ganancia.

Diversos obstáculos dificultan, pues, la comprensión del niño. Sin entrar ahora a analizarlos en detalle (ver Delval y Echeíta, 1991), podemos señalar que el niño tiene dificultades con los cómputos, dificultades para realizar operaciones aritméticas, por lo que no puede separar el precio por unidad y el precio al por mayor. Pero además hay obstáculos de tipo moral para entender la idea de ganancia: sería injusto cobrar más de lo que cuesta, sería como aprovecharse, o incluso robar. Sólo más tarde el niño va a ser capaz de diferenciar el ámbito de las relaciones personales, de amistad, que están regidas más directamente por normas de tipo moral, y el ámbito de lo económico, y entender que éste está regido por otras normas. En el cuadro hemos resumido las dificultades para comprender el problema de la ganancia. 


\section{Dificultades para comprender la ganancia}

\begin{tabular}{ll}
\hline $\begin{array}{l}\text { Se pueden agrupar en dos tipos, las de tipo cognitivo y la de tipo sociomoral, siempre teniendo en cuenta que operan } \\
\text { conjuntamente. }\end{array}$ \\
$\begin{array}{ll}\text { 1. Dificultades de tipo cognitivo son en esencia dificulta- } & \text { 1a. Centración sobre un aspecto que destaca con olvido } \\
\text { des para manejar una gran cantidad de información. El suje- } & \text { de los restantes. El niño se concentra en uno de los aspectos } \\
\text { to no es capaz de controlar todos los aspectos del problema } & \text { de la transacción y olvida los otros. Por ejemplo, puede resul- } \\
\text { y se circunscribe sólo a uno de ellos. } & \text { tarle difícil ver al vendedor al mismo tiempo como comprador } \\
& \text { y cuando considera una cosa olvida la otra. }\end{array}$
\end{tabular}

1b. Problemas con los cómputos. Los niños no dominan todavía las operaciones aritméticas necesarias para entender el proceso de compraventa, y sobre todo no son capaces de aplicarlas al caso concreto que se le plantea. Algunos de ellos no consiguen disociar el precio por unidad y el precio al por mayor.

Los adultos sabemos que el coste total es el resultado de la adición de una serie de costes parciales, pero el niño no es capaz de adicionarlos sino que considera cada uno de ellos independiente de los otros, y piensa que el trabajo del fabricante es mayor que el del vendedor y, por tanto, que el precio del fabricante debe ser mayor que el del tendero.

2. Dificultades de tipo sociomoral. Además de los problemas con el manejo de la información, el niño parece partir de unos presupuestos que le dificultan la comprensión del proceso económico. Se trata de creencias de tipo sociomoral, de presupuestos ideológicos, muy arraigados, pero que probablemente también resulten más sencillos desde el punto de vista cognitivo. 2a. Identificación de lo económico y lo moral. Para el niño el mundo económico está regido por leyes morales y no por leyes económicas y el vendedor es un amigo que nos está haciendo un favor, que nos está ayudando, dándonos algo que necesitamos, y por lo tanto no puede cobrar más de lo que le ha costado a él porque eso no estaría bien. Pero esto se apoya además en otra creencia.

2b. El precio fijo. Los niños piensan que las cosas tienen un precio determinado que es el precio justo y el precio es una propiedad de las cosas como lo es el color, el peso o el tamaño.

Pero cuando el niño ha entendido la idea de ganancia aplicada a la tienda, todavía tiene dificultades en otros ámbitos más complejos, como es el banco, según muestran investigaciones de Jahoda (1981).

Hay otros muchos aspectos de la comprensión del mundo económico con los que los sujetos tienen dificultades semejantes, como sobre la fabricación y circulación del dinero (Denegri, 1995; Delval y Denegri, 2002; Denegri y Delval 2002), la determinación de los precios de las cosas, la producción de mercancías, los salarios, etc. (Berti y Bombi, 1981/88).

\section{La estratificación social}

Uno de los aspectos de las representaciones sociales que hemos estado estudiando se refiere a la organización social, a las diferencias económicas entre los individuos, las diferencias entre ricos y pobres y a las posibilidades de cambio entre esas situaciones, lo que los sociólogos llamarían los problemas de estratificación y la movilidad social (Delval, 1994; Enesco, Delval, Navarro, Villuendas, Sierra y Peñaranda, 1995). En una de nuestras investigaciones hacemos preguntas como las siguientes: ¿Qué es un rico? ¿Qué es un pobre? ¿Cómo es un pobre? ¿Cómo es un rico? ¿Se nota en algo que una persona es rica o es pobre?, etc. Luego le pedimos al niño que se autocaracterice, que diga si él se considera rico, pobre o en otra categoría que haya utilizado. Estudiamos también las concepciones de 
la movilidad social: ¿Cómo se hace la gente rica? ¿Cómo han llegado los ricos a serlo? ¿Cómo llega la gente a ser pobre?

En el cuadro hemos recogido ejemplos de respuestas, que hemos categorizado en tres niveles. Un primer nivel, en el que estarían incluidos niños de edades entre 6 y 10/11 años aproximadamente, un segundo nivel entre 10/11 y 13/14 años, y un tercer nivel a partir de los 14 años.

\section{Ejemplos de respuestas sobre la movilidad social}

\section{Nivel I}

Patricia (6;7A) «-¿Cómo se hace la gente rica? ¿Cómo se llega a ser rico? Pues los padres tienen dinero y los niños cuando crecen tienen sus padres. Les dan dinero; entonces cuando se casan ya tienen dinero y pueden ir a las oficinas y ya son ricas... personas $-i Y$ cómo se hace la gente pobre? Pues sus padres no tienen dinero y cuando los hijos crecen, pues son pobres». NAIRA $(8 ; 8 \mathrm{~B})$ - ¿Cómo se hace la gente rica? Pues hay algunas veces que se llega a ser rico trabajando mu duro, de día a noche, de noche a día, de día a noche. Luego ya cuando han rejuntado muchas huchas, o lo que vayan a rejuntar, a donde vayan a meter ese dinero, cogen se compran su casa. Yo creo que lo primero que tenían que hacer..., también la casa, para donde vivir, pero yo creo que lo más importante era tener la salud y la comida. - ¿Y cómo llega la gente a ser pobre? Pues siendo mu vaga, no trabajar...

\section{Nivel II}

Gonzalo $(10 ; 1 \mathrm{~A})$ «- ¿Cómo se hace la gente rica? Pues como sus padres les llevan a un colegio bueno, y ellos trabajan mucho y sacan muy buenas notas, y luego cogen un buen trabajo, y trabajan tanto como sus padres, pues podrían hacerse ricos. $-i Y$ sus padres son ricos también? No, es porque sus padres les han metido en un colegio bueno y les han dado una buena educación. Dice mi madre que como yo voy a un colegio privado tengo más oportunidades que los pobres, entonces tengo que estar aprovechándolo mucho. - ¿Cómo crees que llega la gente a hacerse pobre? Pues sus padres no le pueden dar una buena educación, tienen que ir a colegios públicos. Luego si son muy vagos y no quieren hacer nada, como no les enseñan mucho pues al final, si no son buenos trabajadores, pues se hacen pobres.»

\section{Nivel III}

BERNARDO (16;3A) «-iCómo crees que la gente se hace rica? Hombre yo creo que para hacerse rico hay que trabajar muy duro ante todo y, no sé, siempre mirar alrededor, mirar las alternativas que uno tiene y mirar adelante en vez de mirar justo al momento en que está uno, o sea mirar las consecuencias que podría llevar una cosa que podrías hacer. $-i$ Y qué han hecho los ricos para hacerse ricos entonces? Yo creo que hay ricos, que son ricos porque resulta que han tenido mucha suerte porque han invertido mucho de lo que tenían en una cosa como muy arriesgada y al final han salido ganando y luego a partir de ahí ha sido fácil porque ... ya con ayudantes que tengan o gente así les pueden ir ayudando y entonces asi y a poco a poco van aumentando.

La idea de la movilidad social de los más pequeños es muy limitada y en cierto modo contradictoria, pero con unas contradicciones que el niño no es capaz de ver. Por una parte 
uno nace y se queda como ha nacido, como dice Patricia $(6 ; 7)$, pero por otra parte uno se puede hacer rico o se puede hacer pobre en un instante, porque uno sale a la calle y se encuentra con un monedero y ya se hace uno rico, o pierde su monedero y se hace pobre. Los cambios son bruscos, súbitos, a veces producto del azar. También aparece la idea de que el trabajo es algo importante para conseguir dinero, pero curiosamente en la idea de trabajo que tienen los niños lo importante es trabajar mucho: los que trabajan mucho son los que ganan mucho dinero, los que trabajan poco son los que ganan poco dinero, pero sin tener en cuenta en qué trabajan. Un niño nos explicaba que un albañil gana poco dinero y un ingeniero gana más porque el albañil empieza a trabajar a las diez y termina a las cinco, mientras que el ingeniero entra a las ocho y está trabajando hasta las nueve de la noche. Él sabía, posiblemente por informaciones que le han llegado, que un ingeniero gana más que un albañil, pero por otra parte como no diferencia la cualidad de los trabajos, lo tenía que explicar apoyándose en las horas que trabajaba cada uno de ellos. Así pues, para los niños de este nivel, el trabajo es un elemento esencial para el cambio de nivel social, pero no influyen otros elementos, no influyen los estudios, no influye el tipo de trabajo que se haga, sino que sólo se considera la cantidad de trabajo que se realice.

En el segundo nivel, como se ve en la entrevista de Gonzalo (véase el cuadro), ya aparece la idea de buen trabajo y de un proceso que comienza por estudiar en un colegio bueno. La idea que transmiten estos niños es que hay dos vías para situarse socialmente, la buena y la mala. Si uno se pone por el buen camino y empieza a hacer las cosas bien, uno ya sigue encarrilado y llega al triunfo social y a una buena posición económica, si uno va por el mal camino, que es no trabajar, no obedecer, no hacer las cosas, entonces no se llega. Hay una diferencia con los niños anteriores porque en estos niños aparece ya la idea de un proceso, hay una serie de pasos para hacerse rico, pero son todavía muy automáticos, de tal modo que una vez iniciado el camino, se va a llegar necesariamente. Aparece una diferenciación clara de los tipos de trabajo: hay trabajos buenos y trabajos malos y no depende únicamente de la cantidad de trabajo, sino de la cualidad.

Finalmente un chico de 16 años, como Bernardo, que se sitúa en el tercer nivel, nos da otro tipo de respuestas. La mención que hace a que hay que considerar las consecuencias de la propia acción y las distintas alternativas sería característica del pensamiento hipotético deductivo tal y como lo describen Inhelder y Piaget, es decir hay que concebir un conjunto de posibilidades, situarse dentro de esas posibilidades y elegir el camino que más conviene. Ya no hay un solo camino para el triunfo social, sino que hay diferentes caminos y uno puede irse encontrando obstáculos continuamente. No se trata de situarse en la buena vía, sino que hay que estar en cada momento haciendo evaluaciones de las alternativas que se presentan arriesgándose en muchos casos. Hay una concepción de un proceso, con distintos elementos que tienen relaciones entre sí. Hemos estudiado este problema con niños y adolescentes españoles y mexicanos (en colaboración con F. Díaz-Barriga) y hemos encontrado grandes semejanzas en las explicaciones. 


\section{Niveles en la comprensión de la movilidad social}

\begin{tabular}{|c|c|}
\hline $\begin{array}{l}\text { Nivel I } \\
\text { Cambios súbitos y poco realistas } \\
\text { 6-10 años }\end{array}$ & $\begin{array}{l}\text { Explicaciones basadas en aspectos aparentes y fácilmente observables, sin } \\
\text { que existan referencias a procesos internos u ocultos. La causa principal de } \\
\text { los cambios se debe a la acción libre e individual del sujeto, a su deseo o al } \\
\text { azar. } \\
\text { El trabajo aparece de una manera incipiente, sin diferenciar unos trabajos de } \\
\text { otros, sólo se diferencia la cantidad de trabajo. } \\
\text { Los estratos económicos son poco permanentes y pueden convivir en las ex- } \\
\text { plicaciones del sujeto dos, ideas aparentemente opuestas y contradictorias: } \\
\text { no hay cambios y al mismo tiempo los cambios son fáciles y se producen de } \\
\text { una manera súbita, frecuentemente por azar. } \\
\text { Ausencia de comprensión de las limitaciones externas, como la escasez de } \\
\text { trabajo o la escasez de bienes. }\end{array}$ \\
\hline $\begin{array}{l}\text { Nivel II } \\
\text { Cambios naturales } \\
\text { 10-13 años }\end{array}$ & $\begin{array}{l}\text { 1) Se empieza a tener en cuenta la escasez y la competencia ligada a ella. } \\
\text { 2) Se empiezan a comprender los procesos temporales que constan de va- } \\
\text { rias etapas. } \\
\text { 3) Los sujetos comienzan a concebir relaciones sociales que no son relacio- } \\
\text { nes entre individuos sino que están institucionalizadas, como la relación entre } \\
\text { comprador y vendedor, o entre jefe y empleado, es decir, relaciones entre ti- } \\
\text { pos de funciones y no entre personas. } \\
\text { El trabajo se convierte en la forma principal de cambio y los trabajos se dife- } \\
\text { rencian de acuerdo con su calidad. } \\
\text { Hay un proceso todavía incipiente y una de sus principales características es } \\
\text { que parece que una vez que se ha iniciado ese proceso ya prosigue necesa- } \\
\text { riamente. }\end{array}$ \\
\hline $\begin{array}{l}\text { Nivel III } \\
\text { Cambios posibles } \\
\text { 13-16 años }\end{array}$ & $\begin{array}{l}\text { Capacidad de concebir un mundo de posibilidades hipotéticas y comprensión } \\
\text { de la existencia de intereses comunes a grupos de individuos. El proceso no } \\
\text { es natural sino que presenta muchos obstáculos que hay que vencer. } \\
\text { Habilidad para entender las relaciones entre sistemas distintos. Así, los suje- } \\
\text { tos son capaces de comprender las relaciones entre la fabricación, la distribu- } \\
\text { ción y la demanda de mercancías, o entre la preparación para el trabajo de un } \\
\text { individuo y la creación de nuevos puestos de trabajo por instancias sociales. } \\
\text { Los factores individuales siguen teniendo un peso considerable y se conside- } \\
\text { ran las diferencias de capacidad entre los individuos y el tesón. La voluntad } \\
\text { que aparece ahora es distinta de la que aparecía en la primera etapa que era } \\
\text { más bien simplemente un deseo que no tenía en cuenta los obstáculos que } \\
\text { tenía que superar. Se habla también de diferencias de oportunidades entre } \\
\text { ricos y pobres, que implican factores sociales. }\end{array}$ \\
\hline
\end{tabular}

Resumiendo las ideas que se van formando respecto a la movilidad social, puede decirse que en un primer nivel (véase el cuadro) se habla de cambios súbitos y poco realistas, cambios producidos por el azar, o por el trabajo, que sólo se considera de una manera cuantitativa, mientras que los estratos económicos son poco permanentes. Las diferencias entre ricos y pobres son únicamente diferencias de dinero, no diferencias de educación, de formas de conducta, de formas de vida, de todo un conjunto de factores, que sí consideran los sujetos mayores. Las diferencias se pueden manifestar también en la apariencia física, la cual es muy importante, pero los rasgos siempre son muy extremos y externos, los ricos van con joyas, con coronas, con abrigos de pieles, mientras que los pobres van vestidos con harapos, viven en la calle, no tienen absolutamente nada, son mendigos.

En el segundo nivel los cambios se producen de una manera natural, cuando uno empieza el buen camino ya sigue por él, pero el niño empieza a entender que esos cambios son procesos temporales que se demoran algún tiempo, que no son procesos instantáneos y las relaciones sociales no son únicamente relaciones entre individuos, sino que son relaciones institucionalizadas. El trabajo es la forma fundamental de alcanzar la riqueza pero en 
aquellos trabajos que son buenos, como en profesiones liberales o en actividades que tienen relación con el dinero (como banquero).

\section{Niveles de explicación de diferentes conceptos sociales}

\begin{tabular}{|c|c|c|c|c|}
\hline Nivel & Dinero & Trabajo & Movilidad & Características generales \\
\hline I & $\begin{array}{l}\text { - Elemento simbólico del inter- } \\
\text { cambio. Dar algo a cambio de } \\
\text { algo. } \\
\text { - No se manejan las cantidades } \\
\text { sino sólo el aspecto cualitativo. } \\
\text { - Descubrimiento de los diferen- } \\
\text { tes tipos de monedas y su } \\
\text { equivalencia. } \\
\text { - El precio es una propiedad de } \\
\text { las cosas. }\end{array}$ & $\begin{array}{l}\text { - Actividad remunerada. General- } \\
\text { mente se realiza fuera de casa. } \\
\text { Su carácter permanece oscu- } \\
\text { ro. } \\
\text { - No se comprenden las diferen- } \\
\text { cias de trabajos. } \\
\text { - Remuneración basada en la } \\
\text { cantidad de trabajo. } \\
\text { - Ideas confusas sobre las dife- } \\
\text { rencias de calidad de los traba- } \\
\text { jos. }\end{array}$ & $\begin{array}{l}\text { - O no hay cambio (se nace) o } \\
\text { es súbito por medio de recibir } \\
\text { o encontrar dinero. } \\
\text { - Procedimientos: azar, lotería, } \\
\text { trabajo (sin especificar). } \\
\text { - Conexión oscura con trabajo y } \\
\text { con dinero. }\end{array}$ & $\begin{array}{l}\text { - La realidad es inmediata y } \\
\text { perceptiva. } \\
\text { - Rasgos aparentes y poco ela- } \\
\text { borados. } \\
\text { - No hay sistemas. } \\
\text { - La sociedad tiene un orden ra- } \\
\text { cional hecho para satisfacer } \\
\text { las necesidades humanas. } \\
\text { - Hay abundancia, no se entien- } \\
\text { de la escasez. } \\
\text { - Relaciones sólo personales. }\end{array}$ \\
\hline II & $\begin{array}{l}\text { - El valor de las mercancías está } \\
\text { determinado por el trabajo y la } \\
\text { escasez (demanda). } \\
\text { - Descubrimiento del mercado } \\
\text { como regulador de los precios. } \\
\text { - Idea de ganancia en la tienda. }\end{array}$ & $\begin{array}{l}\text { - Comprensión de la escasez: no } \\
\text { hay trabajo para todos. } \\
\text { - Diferencias de calidad entre } \\
\text { trabajos. } \\
\text { - Importancia de la preparación y } \\
\text { la educación. } \\
\text { - Comienzan a comprender la } \\
\text { competencia entre actores que } \\
\text { compiten por lo escaso. } \\
\text { - Se puede crear más trabajo } \\
\text { pero sin comprender las limita- } \\
\text { ciones. }\end{array}$ & $\begin{array}{l}\text { - Cambio matizado y gradual. } \\
\text { - Procedimientos múltiples y } \\
\text { complementarios. } \\
\text { - Una vez iniciado el proceso se } \\
\text { desarrolla naturalmente. } \\
\text { - Importancia de la preparación. } \\
\text { - Competitividad individual. } \\
\text { - Depende de la voluntad y el } \\
\text { empeño. }\end{array}$ & $\begin{array}{l}\text { - Descubrimiento de las restric- } \\
\text { ciones o resistencias de la rea- } \\
\text { lidad. } \\
\text { - Los recursos sociales son es- } \\
\text { casos. } \\
\text { - Competencia individual por lo } \\
\text { escaso. } \\
\text { - Relaciones sociales (asalaria- } \\
\text { do, jefe, vendedor) distintas de } \\
\text { las personales (amigo). } \\
\text { - Comprensión de sistemas sim- } \\
\text { ples y de relaciones entre sis- } \\
\text { temas simples. } \\
\text { - Comprensión de procesos dia- } \\
\text { crónicos. }\end{array}$ \\
\hline III & $\begin{array}{l}\text { - Descubrimiento del capital y de } \\
\text { la propiedad de medios de pro- } \\
\text { ducción. } \\
\text { - Aparece la figura del empresa- } \\
\text { rio. } \\
\text { - Ideas sobre el beneficio del pro- } \\
\text { pietario Plusvalía y explotación. } \\
\text { - El papel de los bancos como } \\
\text { prestatarios de dinero y su be- } \\
\text { neficio. } \\
\text { - Generalización de la idea de } \\
\text { ganancia más allá de la tienda. }\end{array}$ & $\begin{array}{l}\text { - Creación de trabajo por cam- } \\
\text { bios en el sistema total. } \\
\text { - Se empiezan a entender las } \\
\text { restricciones debidas al sistema } \\
\text { social. }\end{array}$ & $\begin{array}{l}\text { - Visión más realista de las difi- } \\
\text { cultades del cambio. } \\
\text { - Importancia del punto de par- } \\
\text { tida. Relaciones sociales. } \\
\text { - Papel activo del sujeto en ca- } \\
\text { da momento del proceso. } \\
\text { - Cualidades personales, ambi- } \\
\text { ción, riesgo. } \\
\text { - Evaluación de las posibilida- } \\
\text { des y consecuencias. } \\
\text { - Competencia social. } \\
\text { - La voluntad como forma de } \\
\text { superar los obstáculos socia- } \\
\text { les (sin ignorarlos). }\end{array}$ & $\begin{array}{l}\text { - Consideración de mundos po- } \\
\text { sibles. } \\
\text { - Comprensión de la competen- } \\
\text { cia poniéndose en el lugar del } \\
\text { otro. } \\
\text { - Restricciones sociales. } \\
\text { - Procesos temporales largos, } \\
\text { más allá del individuo. } \\
\text { - Posibilidad de entender rela- } \\
\text { ciones complejas entre múlti- } \\
\text { ples sistemas. } \\
\text { - Sesgos ideológicos. } \\
\text { - La equidad frente a la igual- } \\
\text { dad. }\end{array}$ \\
\hline
\end{tabular}

Finalmente en el tercer nivel podríamos hablar de cambios posibles, de un mundo de posibilidades hipotéticas en el cual el niño entiende las relaciones entre diversos sistemas. Por ejemplo, los niños más pequeños (del primer nivel) piensan que para resolver el problema de los pobres lo que hay que hacer es darles dinero, ofrecerles una limosna, practicar la caridad. Los niños del nivel intermedio ven también la caridad como una solución, pero empiezan a ver limitaciones porque se dan cuenta que hay muchos pobres, y no se trataría de dar individualmente, sino de que el gobierno, en España el rey, en México el presidente, tendría que decir a los ricos que dieran dinero a los pobres de una manera general. En cambio los chicos del tercer nivel niegan la posibilidad de que dar dinero sea una solución y hablan de dar trabajo o de dar educación, pero dar trabajo tiene sus limitaciones porque es necesario crear ese trabajo. El trabajo no es algo que sea abundante como piensan los pequeños, sino que es necesario disponer de los puestos de trabajo y eso implica ya la 
intervención de muchos elementos sociales, dentro de una concepción mucho más rica, que es la que llegan a formar estos chicos mayores acerca de los fenómenos sociales. Todavía son ingenuos en muchas cosas y no entienden muchos aspectos del funcionamiento social, pero son capaces de empezar a ver la realidad social con toda la dificultad que supone encontrar soluciones a estos problemas. En el cuadro hemos resumido algunas de estas características comparándolas con las que se producen en conceptos relacionados como son el dinero y el trabajo, y hemos señalado igualmente algunos rasgos generales que aparecen en los problemas de la comprensión de varios conceptos sociales (Delval, 1994).

Estamos realizando estudios sobre la comprensión de otros problemas sociales y encontramos que las explicaciones que nos van dando los sujetos siguen un orden y van pasando de explicaciones más simples a otras más complejas, en las que no sólo aumenta el número de elementos que se tienen en cuenta sino también las relaciones entre los elementos. Descubrimos que su evolución sigue unas pautas muy parecidas a las de otros conocimientos sociales y puede describirse también a través de esos tres niveles.

\section{El prestigio de las profesiones}

Un tipo de investigación clásica en la sociología lo constituye el estudio del prestigio de las profesiones. Numerosos trabajos realizados desde los años 20 y en muchos países han señalado que los sujetos ordenan jerárquicamente las profesiones de una forma muy semejante con independencia de la sociedad y la clase a la que pertenecen. Algunos estudios se han ocupado de las ideas de los niños sobre el prestigio y también han encontrado que sus ordenaciones coinciden desde temprana edad con las de los adultos.

Hemos examinado esta cuestión (con Ana Peñaranda) en sujetos desde 8 a 20 años y hemos encontrado que efectivamente las ordenaciones de los sujetos a partir de los 10-11 años son bastante semejantes a las de los adultos. La técnica que se suele emplear consiste en pedir a los sujetos que ordenen las profesiones de acuerdo con su 'bondad' sobre una escala. Pero conviene señalar que aunque la media de las ordenaciones de los sujetos coincide básicamente en las distintas edades, hay bastantes diferencias individuales que los análisis estadísticos minimizan.

Pero nos ha parecido que lo más importante no es saber cómo jerarquizan los sujetos las profesiones sino en virtud de qué criterios lo hacen. Para ello les hemos preguntado las razones por las que sitúan cada profesión en un lugar, referido a 13 profesiones bien conocidas por ellos.

Lo que nos ha mostrado el análisis de las respuestas es que los sujetos reciben desde muy temprano información sobre las distintas profesiones y en particular sobre las que se sitúan en los lugares superiores o inferiores. Los médicos son siempre muy apreciados porque curan a la gente y se ocupan de su salud y su bienestar, mientras que los obreros, o barrenderos son poco valorados porque trabajan en condiciones más duras y ganan menos dinero. Los índices sociales de la valoración son muy numerosos y se transmiten por múltiples vehículos. Podría decirse que el prestigio es una representación social que está en la sociedad, es compartida y se transmite por los otros.

Pero los sujetos tienen que manejar también los rasgos de cada profesión que la hacen 'buena' o 'mala'. No sólo aprenden a valorarla sino los criterios que la hacen buena o mala. 
La preparación necesaria para desempeñar la profesión, las condiciones en las que se desempeña, la remuneración que se recibe, la fama o el poder que proporciona a los que la ejercen y las consecuencias que tiene para los otros, son rasgos que determinan la valoración que el sujeto hace. Esos rasgos son también transmitidos socialmente y los sujetos, desde pequeños, aprecian recibir una alta remuneración, tener un trabajo cómodo (y se establece claramente la distinción entre profesiones de 'cuello blanco' y de 'cuello azul'), gozar de fama o poder, o ser útiles a los demás.

Analizando las respuestas de los sujetos encontramos que frecuentemente se produce un conflicto entre la información sobre el prestigio global y las razones por las que ese prestigio se establece. Por ejemplo, la profesión de futbolista se considera poco útil socialmente (porque sólo juegan y si no hubiera futbolistas no pasaría nada), pero se les atribuye remuneraciones muy altas y fama. La profesión de policía es muy valorada socialmente porque detienen a los malos y mantienen el orden, pero la remuneración es baja y las condiciones de trabajo poco agradables. El maestro es muy valorado pero también se sabe que la remuneración no es muy alta. Así se producen contradicciones que a los sujetos pequeños les resultan difíciles de resolver, lo que les lleva a cambiar sus explicaciones en el curso de la entrevista y produce que las ordenaciones de distintos sujetos sean bastante diferentes, aunque la media se aproxime a la de los adultos.

Lo interesante de este análisis es que nos permite ver que aunque el sujeto está manejando una información socialmente disponible, la tiene que integrar por sí mismo. Reglas sociales como «una profesión en la que se ayuda a los demás es valiosa», «una buena profesión es aquella en la que se gana mucho dinero», y otras muchas parecidas, compiten ente sí y el sujeto tiene que resolver el conflicto entre esas reglas y poner un orden, pero esto es algo que sólo consigue paulatinamente y que parece depender de su nivel de desarrollo intelectual.

Creemos que uno de los aspectos fundamentales de la comprensión de la sociedad es ser capaz de resolver las contradicciones entre las normas. El niño aprende pronto las normas, pero las toma como absolutas y sin excepciones. Son reglas rígidas, es decir que una vez establecidas no pueden modificarse. Sin embargo, lo característico de las normas sociales es precisamente que son flexibles e incluso que pueden no respetarse. En un interesante trabajo Furth y McConville (1981) señalaron que la diferencia entre los adolescentes jóvenes y mayores es que estos son conscientes de la necesidad de compromisos en la vida social, de que los hechos sociales pueden contemplarse desde distintos puntos de vista y de que distintos participantes pueden tener razón, por lo que las soluciones que se imponen son aquellas en las que cada uno cede parte de su razón para establecer un acuerdo con otros.

\section{Los derechos de los niños}

Los niños son seres vulnerables desde el punto de vista social debido a su dependencia que les hace tener que apoyarse en los adultos para satisfacer sus necesidades. Por ello pueden estar sometidos a abandono o negligencia por parte de las personas que les cuidan, o puede suceder simplemente que éstas no se ocupen de ellos de forma adecuada por ignorancia o incapacidad. Las declaraciones de derechos de los niños, y en especial la de las Naciones Unidas de 1989 (ONU, 1989) tratan precisamente de especificar los derechos que deben respetarse. Esos derechos derivan de las necesidades de los niños (López, et al., 1995 ), y tienen características específicas en relación con los derechos humanos en general porque los niños no los pueden defender como los adultos (Delval, 1995). Pero para que existan garantías del respeto a sus derechos es importante que los niños los conozcan y los entiendan. 
Esta situación es la que nos llevó a plantearnos realizar una investigación sobre cómo conciben los niños sus propios derechos (Delval, del Barrio y Espinosa, en preparación). Aunque existen numerosos trabajos en torno a los derechos de los niños, son casi inexistentes los estudios que se ocupan de investigar qué ideas tienen los propios sujetos de los derechos sobre cómo se pueden proteger. Conocer las ideas de los niños sobre este asunto puede contribuir muy eficazmente a encontrar las formas más adecuadas para garantizar esos derechos. Pero este estudio tiene un interés más amplio, ya que la concepción que tengan sobre sus derechos nos puede informar también sobre su concepción del orden social en general y sobre el funcionamiento de la sociedad.

Una de las razones principales que pueden explicar la ausencia de estudios sobre este asunto se encuentra en el hecho de que preguntar directamente a los niños sobre cuáles son sus derechos proporciona poca información porque, sobre todo los pequeños, no tienen ideas sobre qué es un derecho y no están familiarizados con las denominaciones adultas. Por ello era necesario encontrar otras maneras de abordar el problema. Nosotros decidimos hacerlo planteándoles una serie de situaciones por medio de historias muy breves en las que se violaban o entraban en conflicto algunos de los derechos de los niños y niñas. Para hacer más verosímil la situación y descubrir la concepción que tenía cada sujeto se le decía que el personaje principal de la historia era un niño/niña de edad semejante a la suya. Tras la historia le preguntábamos cómo la entendía, si en ella se producía una violación de un derecho y cuáles serían las posibles soluciones y la intervención de otras personas para restablecer el derecho.

De entre los múltiples derechos que se recogen en la Convención sobre los derechos del niño y la niña de 1989, seleccionamos algunos teniendo en cuenta su relevancia y que pudieran ser comprendidos por niños relativamente pequeños y realizamos un estudio piloto. Finalmente elegimos historias que trataban sobre el derecho a la educación, alimentación, atención médica, información, así como una situación en la que se planteaba un conflicto entre derechos de los niños y de los adultos, y otra referente a un falso derecho (el de un niño que quería dejar de estudiar). Finalmente terminábamos con una serie de preguntas generales sobre lo que entienden por derechos y cuáles son, que tenían más sentido planteadas al finalizar la entrevista y tras haber hablado durante unos 30-45 minutos sobre el asunto. En total se planteaban ocho situaciones, además de las preguntas generales. Como ejemplo mencionamos dos historias.

\section{Derecho a la Educación}

Unos padres no querían que su hijo (hija) fuera a la escuela porque preferían que se quedara en casa para ayudar en trabajos domésticos y porque decían que aprender no servía para nada. El niño no podía ir al colegio a estudiar. ¿Tú crees que está bien que sus padres hagan eso? ¿Tú crees que algún padre lo hace? ¿Tú crees que lo puede hacer? ¿Qué podría hacer el niño? ¿Podría hablar con alguien?

\section{Derecho al juego: Conflicto de derechos}

Un grupo de niños juega al fútbol en el patio de la casa donde viven, pues no tienen otro sitio cercano dónde puedan jugar. Los vecinos se quejan porque hacen mucho ruido y, de vez en cuando, rompen algún cristal, y quieren prohibir que los niños jueguen allí. Pero los 
niños no tienen otro sitio donde ir. ¿Tú crees que eso puede pasar? ¿Qué te parece? ¿Tú crees que tienen razón los vecinos o los niños? ¿Cómo se podría solucionar? ¿Tú crees que los niños podrían hacer algo? ¿Dónde podrían ir? ¿A quién se lo podrían decir? ¿Tú crees que les harían caso?

Examinamos a 90 sujetos de 8 a 16 años, de ambos sexos, mediante entrevistas abiertas en profundidad utilizando el método clínico (Delval, 2001). Además realizamos sesiones de grupo con adolescentes.

\section{Respuestas sobre el derecho a la educación}

\section{Nivel I}

BeATRIZ $(8 ; 6)$ ¿Qué raro, no? - ¿Te parece raro? ¿por qué? ¿tú crees que esto no pasa? Yo creo que no, porque los padres quieren que sus hijos trabajen y ya de mayor tengan su trabajo. - ¿Tú crees que todos los padres quieren eso? Yo creo que sí. Por ejemplo los míos si quieren eso, quieren que vaya a la escuela y que no falte.

Alvaro $(8 ; 7)$ - ¿Entonces qué puede hacer el niño si los padres no quieren que vaya al colegio? Pedírselo por favor. $-i$ Y si los padres no hacen caso porque dicen que no, que es mejor que se quede en casa a hacer las tareas? Pues decirle que alli aprende más que en casa.

BlanCA $(11 ; 0)$ ¿Tú crees que esto puede pasar? Pues... no, porque tendría que aprender, porque si no luego no puede estudiar una carrera... y no puede ganar dinero. Luego a lo mejor es pobre y quiere trabajar. $-i \mathrm{Y}$ los padres piensas que pueden hacer eso? No. ¿No pueden? No. - ¿Por qué? Porque tendrían que pensar que no ganaría dinero. $-i$ En este caso tú qué crees que podría hacer la niña? Decírselo a sus padres otra vez, insistir. - Y si los padres son unos «cabezotas» y la siguen diciendo que se quede en casa, ¿con quien podría hablar la niña? Pues..no sé...con sus familiares, con su tía para que intentara convencerlos. - ¿Y si no los convence? ¿Piensas que podría hablar con alguien o ir a algún sitio a hablar? Pues...venir al colegio a hablar.

Nivel II

JAVIER $(12 ; 11)$ Tú crees que esto puede suceder o que sucede? Si puede suceder, en mi mismo colegio hay una familia que le ha pasado, pero no tengo ni idea, era un chico que iba a pasar a $2^{\circ}$ de BUP y su padre mismo le dijo que quería que trabajara en la tienda $y$, pues nada, y se quedo a trabajar. Pero normalmente no pasa, vamos, digo que una de cada 200 o 300 familias pasará eso. - Tú crees que es una situación correcta lo que hacen los padres? Depende. Si es realmente importante que les ayuden por causas económicas, de dinero, pues sí. Pero bueno, si tampoco es lo necesario, si es solamente porque a ellos no les gusta, y se supone que es lo mejor para sus hijos, pues entonces actúan injustamente.

\section{Nivel III}

RodRIGO $(16 ; 0)$ ¿Tú crees que está bien que los padres hagan eso? Pues no, porque entre otras cosas, según los derechos del niño, el niño tiene derecho a una educación, entonces me parece mal que los padres se lo nieguen. O sea, si el niño tiene derecho a la educación, me parece justo que la reciba. - ¿Qué es eso de los derechos del niño? Pues por ejemplo, 
los derechos que tienen los niños, por ejemplo, tienen derecho a una vivienda digna, derecho a la educación, tienen unos cuantos más pero es que no me acuerdo. -Entonces tú me estás diciendo que el niño tenía derecho a recibir una educación. ¿Qué significa eso de tener derecho? Pues que, yo lo que entiendo por derecho a una educación es que nadie le puede prohibir que la reciba, es lo que entiendo yo. $-\mathrm{Y}$ entonces si nadie le puede prohibir que la reciba pero de hecho en este caso ese derecho se está violando, se está transgrediendo, ¿qué podría hacer el niño para que ese derecho se cumpliera, para poder ir a la escuela? Teniendo en cuenta que es un niño de diez años no se le va a tener mucho en cuenta, es un problema que tendría para poder ir. No sé, yo creo que a lo mejor yendo a la escuela, hablando con profesores o algo así no creo que le tomasen mucho en serio. ${ }_{-i Y}$ si el niño fuera un poco más mayor? ¿Cuánto? -Imagínate quince o dieciséis. Yo creo que ya conociese los derechos ya podría exigirlos o sea, ir al colegio y decir «yo aquí vengo y quiero...», no sé, sería hablarlo con..., poniéndote en los familiares a alguien que sí que tuviese confianza, hablar con esa persona, primero ir a la familia y si la familia no tuviese respuesta ir al colegio o a donde fuese.

Los resultados de nuestro estudio nos han permitido comprobar que las explicaciones acerca de los derechos van cambiando de una manera bastante regular y que siguen un proceso semejante respecto a los distintos derechos, aunque también existen algunas diferencias entre ellos. Hemos podido situar a nuestros sujetos en tres niveles de explicación. El primero, en el que se encuentran los sujetos entre los 8 y 11 años los niños no entienden las violaciones de los derechos y les parecen muy extrañas, por lo que a menudo consideran las historias como inverosímiles. Suelen confundir los derechos con las obligaciones y no son capaces de encontrar soluciones satisfactorias. Proponen que el niño hable con las personas que violan el derecho y que trate de convencerles o buscan soluciones absurdas, cuyas consecuencias no son capaces de establecer.

En el segundo nivel, en el que se sitúan los sujetos entre los 11 y los 13 años empieza a aparecer una intuición todavía confusa de la existencia de derechos y las historias les empiezan a parecer más verosímiles. Diferencian también el grado de violación según la intención de la persona que viola el derecho explícitamente.

En el tercer nivel, en el que se sitúan los sujetos a partir de los 14 años, la noción de derecho se aparece más clara, los sujetos son conscientes de la existencia de derechos que de alguna manera están garantizados, se diferencia entre los derechos y las obligaciones y se establecen relaciones entre ellos, y se empiezan a proponer soluciones más adecuadas.

A través de las respuestas vamos observando los progresos en la comprensión del orden social, en donde se termina viendo que existen intereses contrapuestos y debe haber garantías para poder ejercer esos derechos. Para que se vea cómo va cambiando el tenor de las respuestas reproducimos algunas respuestas de sujetos de distintos niveles a la historia del derecho a la educación. Se pueden observar los cambios en la comprensión de la historia y en las soluciones que proponen.

Respecto a los derechos que se consideran más importantes, además de los derechos sociales, como la educación, atención médica o alimentación se tiende a mencionar la necesidad de participación por parte de los niños y adolescentes en las actividades y decisiones que les afectan directamente. Los mayores reclaman con insistencia su derecho a participar y a ser escuchados por los adultos. Este es un derecho que se empieza a considerar como muy importante, pues facilita la integración del niño en la vida social (Franklin, 1995). Como 
veremos más adelante se pasa de una concepción del orden social que es visto como racional, armónico y encaminado a satisfacer las necesidades de los individuos, sin que sea necesario establecer los derechos, a una concepción en la que se producen conflictos que tienen que ser resueltos mediante la negociación y también mediante la aplicación de las leyes.

\section{La idea de Dios y la religión}

Para terminar esta somera revisión de las concepciones de los niños sobre el mundo social, vamos a presentar algunas de las respuestas que nos han dado en una investigación sobre la idea de Dios. Podríamos pensar que las concepciones sobre Dios que tienen los niños deberían ser un ejemplo claro de ideas recibidas de los demás, de los adultos, a través de la transmisión en la escuela o en la parroquia, de los padres, ya que los sujetos no pueden formar esas días a través de su propia experiencia. Podrían ser entonces un buen ejemplo de representaciones sociales en el sentido de Moscovici en donde la actividad del individuo tuviera un papel muy limitado.

Ello es lo que nos llevó a realizar una investigación (que constituyó la tesis doctoral de Irene Muriá, 1995, dirigida por J. Delval) sobre este asunto que ha sido relativamente poco explorado hasta ahora, si excluimos algunas investigaciones entre las que destaca la de Heller (1986). En nuestra investigación nos planteamos estudiar las explicaciones sobre Dios y otros asuntos relacionados como el origen del mundo y de la vida, en donde se les preguntaba por la creación de la tierra; el origen de Dios; las características con las que los niños conciben a Dios; la muerte y la existencia después de la vida terrenal; y las posibilidades de que exista una comunicación con Dios. Además se les pedía a los sujetos que realizaran un dibujo de cómo se representa Dios o algún aspecto relacionado con las cosas de las que habíamos hablado. En lo que sigue nos vamos a limitar a hablar sobre las características de la divinidad y la posibilidad de comunicación con ella.

La naturaleza del problema hace que naturalmente diversos aspectos del conocimiento social no puedan manifestarse. Por ejemplo no se ve claro cómo pueden aparecer relaciones institucionalizadas frente a relaciones personales, o el papel de los procesos temporales, ya que Dios, por su propia naturaleza es algo intemporal. Pero a pesar de ello es interesante observar las ideas infantiles desde esta perspectiva de diferentes niveles de comprensión y explicación de la realidad social, que creemos que pueden distinguirse también en este asunto, lo cual nos parece que constituye una cierta confirmación de nuestras ideas.

Encontramos que las concepciones de los sujetos más jóvenes, hasta los diez-once años aproximadamente, que situamos en el Nivel 1, vienen a coincidir con la religión aprendida aceptando en gran medida la concepción tradicional de la Biblia. Los más pequeños, que todavía no conocen perfectamente esa descripción hacen intervenir elementos fantásticos inventados por ellos. Las ideas principales que se manifiestan las podemos resumir en las siguientes:

En general los sujetos de este nivel conciben a Dios como una persona, de sexo masculino, con los atributos físicos que se le atribuyen en las imágenes de los libros, como se pone de manifiesto en las respuestas de Yago de 6 años.

La participación de Dios en la vida cotidiana de las personas es algo que resulta todavía relativamente confuso, pero en general se tiende a pensar que Dios se ocupa de cada una de las cosas que acontecen. 
El lugar de Dios es el cielo, donde vive rodeado de los que se han muerto, de los ángeles y de las personas allegadas, como la Virgen María, San José y Jesús.

La comunicación con Dios resulta posible a través de la oración y para eso se le reza, para pedirle cosas concretas.

En un segundo nivel constituye un camino hacia una espiritualización de Dios, aunque todavía este teñido de rasgos materiales. Se le sigue considerando como una persona con características materiales, pero se empieza a dudar de esa misma creencia. Empiezan a manifestarse conflictos entre la religión aprendida y la reflexión que realizan los sujetos. Dios empieza a verse como algo inmaterial.

Dios asume sobre todo funciones morales, es el referente moral último que permite valorar nuestras acciones como buenas o malas.

Surgen dudas sobre la participación de Dios en los asuntos humanos, pues por una parte se sigue pensando que Dios participa en todo, que nada puede suceder sin que él lo quiera, sin su autorización, pero al mismo tiempo se producen conflictos con las cosas malas. Entonces Dios participa en las guerras, pero tratando de que se terminen; cuando alguien muere es porque Dios ya desea que esté con él. Hay pues un conflicto entre que Dios tenga el control de todo, lo vea todo, y también la libertad humana, lo que se resuelve de una manera rudimentaria señalando que Dios participa fundamentalmente en las cosas buenas, procurando siempre ayudar a los humanos.

\section{Dos ejemplos de respuestas sobre la idea de Dios}

La comparación de las respuestas de estos dos sujetos de 6 y casi 15 años resulta muy ilustrativa y nos permite ver los cambios que se producen en esos años, que hay que atribuir a una labor de elaboración y construcción de los propios sujetos

\section{Nivel I}

Yago $(6 ; 4)$ - ¿Podrías explicarme cómo crees tú que es Dios? Él dijo que se haga todo el Universo y el mundo, y así. - ¿Pero cómo es él? Con barba, con bigote, con pelo hasta aquí, y también muy triste. $-{ } \mathrm{Y}$ tú crees que puede ser hombre, mujer o ninguna de las dos, o las dos cosas? Hombre. - ¿Porque crees que es hombre? Porque yo tengo muchísimos libros de él en mi clase. - ¿Y por algo más? Y también porque yo ya me lo sé de memoria. - ¿Qué es lo que te sabes de memoria? Lo de que es hombre, que puede volar un poco. - ¿Puede volar? Si, hasta aquí. - ¿Y algo más? Que es diferente a los otros hombres. - ¿Es diferente? Es mágico, su magia es de verdad. — ¿Magia de verdad? ¿Qué puede hacer? Nada más puede crear cosas pequeñas, puede decir «ique se ponga aquí un lápiz!» y aparece, «ique se ponga una caja de caramelos!» y aparece. - ¿Y si dijera un hombre aparecería también? Eso es un poco grande. Tendría que hacer como muchísima magia, y él no tiene tanta. (...) ¿En dónde piensas que vive Dios? Antes vivía en un castillo, y ahora vive en el cielo. - ¿Y vive solo? No, con los angelitos, con los muertos que han ido al cielo, con mucha más gente... con el padre de mi madre que murió, se le paró el corazón cuando estaba durmiendo la siesta. - ¿Y qué es lo que hace Dios, a qué se dedica? ¿Dios? pues... a mandar en el cielo, que nadie se pelee con nadie. - ¿En el cielo sólo? En el cielo... aquí, mirar para abajo y lanzar magia. - ¿Lanza magia también? Sí, y los angelitos de esos que tienen flechas en el amor, las lanzan desde abajo, las lanzan para abajo, dan a quien sea malo, y ya se hace bueno. (...) ¿Tú crees que es 
posible hablar con Dios? Sí, cuando rezas, el padre, el hijo, Espíritu Santo, amén, es cuando le estás hablando. - ¿Y él te responde? No. - ¿Si tú le pides algo él te lo concede a veces? A veces sí y a veces no. - ¿Qué te gustaría preguntarle a Dios si lo vieras? Que no haiga (haya) niños pobres, como un amigo mío de segundo, que dijo eso y se está haciendo el deseo. - ¿Y alguna otra cosa? Sí, que todos los que sean pobres en el mundo los pueda hacer Dios ricos. _ ¿Algo más? Nada más.

Nivel III

Marta $(14 ; 11)-¿$ YY podrías explicarme cómo es Dios para ti? ¿Cómo te imaginas que es? No sé, es que no le pongo cara ni figura sabes? yo pienso que es alguien que... algo que te escucha, y aunque tú no lo sepas a la mejor te intenta comprender, algo que te inspira esperanza, que te inspira seguridad, y no sé... algo como cobijo en el futuro y si, yo creo que si que es eso. - ¿No es una persona? No, es algo abstracto que te da confianza, que te da esperanza y te cobija, y ya está. - ¿Y tú crees que puede tener algo de masculino, femenino, las dos cosas, o ninguna de las dos cosas? No yo creo que no, es que eso tampoco lo miro porque, yo creo que si es algo abstracto, que da igual que sea masculino, femenino, mientras te dé confianza y eso que da igual. $-i Y$ dónde piensas que está? hay algún lugar especial dónde pueda estar? No, yo creo que está en todos sitios, que siempre va contigo, es como si cada uno tuviese un Dios, su angelito de la guarda, pues igual pero para todos, que sirve para todos. $-i \mathrm{Y}$ no tiene un lugar en especial dónde estar? No yo creo que no, que siempre está con la persona, con la propia persona, aunque luego digan que está en el cielo y todo eso, yo creo que si, que siempre está con la persona, y en el momento en que la necesita pues... - iNo crees que está en el cielo? Hombre! si, pero eso es aparte, o sea... — ¿Tú crees en el cielo? Si yo creo que si, porque sino en que tengo que creer? (riéndose) tengo que creer en algo no? para... no sé... yo creo que es como si fuese algo abstracto que llevamos todos, entonces que cuando te mueres, pues como tienes que ir a algún sitio, pues tendrás que ir al cielo, y de allí seguirá contigo, entonces pues eso, que está con cada uno y que cuando te mueres pues te acompaña. (...) ¿Tú crees que es posible hablar con Dios? ¿Hablar? ¿Que te conteste? -Comunicarte con él, o que te responda. Yo creo que eso es ya parte de la conciencia, que tú tienes tantos deseos.., que una persona tiene tantos deseos de que te conteste de verdad, que a la mejor piensas la respuesta que él te podría dar y dices jay, me ha contestado! y has sido tú mismo, tu conciencia, y como tampoco sabes si ha sido la conciencia, o ha sido el diablo o el demonio o ha sido quien sea, pues piensas que ha sido Dios, y ya está, pero yo creo que es todo de la conciencia, cuando alguien dice yo he hablado con Dios, es por eso.

En el tercer nivel Dios es concebido claramente como algo abstracto y se rechaza la primera idea de que tenga rasgos concretos o sexo, no se le aplica que sea masculino o femenino. Dios es concebido sobre todo como una idea interna, que tiene que ver con la conciencia de los individuos. Incluso para muchos sujetos el problema de la existencia de Dios pasa a ser algo secundario, sin que eso suponga que nieguen su existencia. Simplemente Dios es un sentimiento interno que te sirve de consuelo y que tiene un papel muy importante para dirigir la acción moral. Cuando hacemos algo que está mal experimentamos un remordimiento o la sensación de que hemos hecho algo que no se debería hacer.

Dios no está entonces en ningún lugar específico ni físico sino que está en todas partes y en ninguna a la vez. Dios además no se ocupa directamente de los asuntos humanos, sino que 
su función fue poner las cosas en marcha, pero luego son los humanos los que tienen la responsabilidad de lo que hacen porque son libres.

Las creencias en la divinidad de estos sujetos mayores se tornan mucho más complejas y personales que las de los pequeños. Se observa claramente en ellas que hay muchos elementos producto de la reflexión sobre lo que se les ha enseñado. Un ejemplo de ello son las respuestas de Marta $(14 ; 11)$

Es probable que en este nivel coexistan orientaciones que no suponen un avance evolutivo, sino maneras de ver el mundo de una complejidad semejante, orientaciones propias de cada individuo. Algunos tienden a ver a Dios como algo mucho más abstracto e insisten en el aspecto de estado subjetivo, mientras que otros lo siguen considerando como un ser distinto de nosotros, como transcendente. Para unos lo más importante son precisamente esas vivencias internas, sin que les preocupe tanto el aspecto de la realidad, el aspecto ontológico. Es probablemente también una concepción más mística en la que podemos comunicarnos con Dios, pero que en realidad es hablar con nosotros mismos. Los que tienen una concepción más realista son precisamente los que ponen más en duda que podamos comunicarnos con él.

Estos breves ejemplos nos permiten observar como en estas ideas hay también un proceso de elaboración personal y que están lejos de ser simples copias de algo recibido

\section{Los niveles del conocimiento social}

A lo largo de diversas investigaciones que hemos realizado en los últimos años, sobre las representaciones de niños y adolescentes acerca de la sociedad, hemos ido comprobando que cuando les pedimos que nos expliquen el funcionamiento de una parcela amplia de la realidad social y examinamos sujetos de distintas edades hasta la adolescencia los tipos de explicaciones que nos ofrecen siguen algunas pautas constantes, como ya apuntábamos al hablar de la movilidad social. Las ideas sobre el origen y la circulación del dinero, sobre el prestigio de las profesiones, sobre los jefes y sus funciones, sobre los derechos de los niños, sobre la función del profesor en la escuela o incluso sobre la idea de dios pueden describirse siguiendo una progresión en tres niveles, que pueden subdividirse y especificarse en algunos casos, y que tienen las siguientes características (Delval, 2001):

En un primer nivel, que se extiende hasta los 10-11 años (téngase en cuenta que las edades son sólo aproximadas), los sujetos basan sus explicaciones en los aspectos más visibles de la situación, los que pueden observarse a través de la percepción y no tienen en cuenta procesos ocultos que deban ser inferidos. Los pobres son reconocidos por su aspecto físico y los ricos tienen su dinero en la cartera o en una caja; se puede pasar de pobre a rico encontrando dinero en la calle. Las mejores profesiones son aquellas en las que se ayuda a los otros. No existen propiamente derechos de los niños porque los adultos se ocupan convenientemente de ellos y hacen todo lo necesario para su bienestar; si los padres u otras personas impiden a los niños hacer algo que les corresponde lo único que puede hacerse es hablar con ellos y tratar de convencerles, o si no aguantarse.

En ese nivel son poco sensibles a la existencia de conflictos, pues tienden a centrarse en un sólo aspecto de la situación en cada momento. Si reconocen la existencia de un conflicto (por ejemplo unos padres que no quieren que su hijo vaya a la escuela en contra de los deseos del niño) no ven soluciones posibles, como no sea dar alternativamente la razón a 
unos o a otro. No se reconoce la existencia de relaciones propiamente sociales, sino que las relaciones son personales, y por ejemplo el maestro ayuda a los niños porque los quiere y quiere que estén bien y aprendan. De esta forma los conflictos sólo se pueden resolver mediante la buena voluntad de las partes.

En un segundo nivel, que se extiende por término medio entre los 10-11 años y los 13-14, los sujetos empiezan a tener en cuenta aspectos no visibles de las situaciones, es decir procesos que deben inferirse a partir de la información de que se dispone. Los procesos incluyen una duración temporal, es decir se desarrollan en un período más o menos largo. Aparece la distinción entre las relaciones personales y las sociales o institucionalizadas: el vendedor no es un amigo que nos proporciona las cosas que necesitamos, sino alguien que desempeña una función social y vive de eso; el maestro se ocupa del aprendizaje de los niños y de ayudarlos porque esa es su función. En la misma línea la asistencia del niño al colegio no es un deseo de los padres sino que está prescrito por una norma social.

Se perciben más claramente los conflictos, aunque lo más frecuente es que no sea posible encontrar todavía soluciones satisfactorias por la dificultad de considerar aceptables distintos puntos de vista. Los sujetos empiezan a evaluar las normas con sus propios criterios e incluso a criticarlas.

En un tercer nivel, que comienza hacia los 13-14 años, los procesos ocultos y, por lo tanto, necesariamente inferidos, ocupan un papel central en las explicaciones. Las distintas posibilidades que se presentan en una situación son examinadas sistemáticamente y el sujeto es capaz de coordinar puntos de vista y de reflexionar sobre lo posible. Los cambios sociales son lentos, incluso muy lentos. Los sujetos poseen mucha más información sobre el funcionamiento social, pero sobre todo saben cómo integrarla o tratan de hacerlo. Uno de los rasgos más claros es que los sujetos intentan encontrar una coherencia en las cosas y abordan directamente los conflictos. La solución de esas situaciones problemáticas se ve en relación con el establecimiento de cesiones por parte de los actores sociales, de compromisos entre una posición y otra, que permite llegar a acuerdos en los que cada parte cede algo de sus derechos. Las reglas se aplican de una manera mucho más flexible y se pueden establecer también compromisos entre ellas. Los sujetos se vuelven críticos con el orden social existente, emiten juicios sobre lo que está bien y no está bien y proponen soluciones alternativas.

Por supuesto en cada aspecto de la realidad social que consideramos aparecen rasgos específicos y propios de ese dominio, pero existen también muchas semejanzas interdominios y parece que en cada uno de los niveles hay como una concepción global de la sociedad y de las relaciones entre los actores sociales. No podemos asegurar a priori que estos niveles de explicación se den en todos los terrenos y eso sólo podrá decirlo la investigación sobre cada campo, pero por lo que hemos visto nos parece que puede hablarse de visiones del mundo distintas que van construyéndose a lo largo del desarrollo.

\section{CONCLUSIONES}

Para terminar querríamos hacer algunas observaciones sobre cómo parece que es la sociedad que el niño concibe, que resulta bastante diferente de la que conciben los adultos. No podemos extendernos ahora sobre las causas a las que esto se debe, pero si nos gustaría señalar algunos rasgos llamativos. Lo que vamos a apuntar puede resultar sorprendente -y 
lo presentamos con todo tipo de reservas, sobre todo en lo referente a lo que sucede en otros medios sociales-, pero creemos que hay datos suficientes para trazar un cuadro como el que vamos a bosquejar.

El niño entiende una realidad social muy distinta de la que vemos los adultos, que nos hemos acostumbrado a concebir el orden social como un terreno de lucha y de competencia de todos contra todos, haciendo nuestro el dictum hobbesiano homo homini lupus. Por el contrario, parece que los niños conciben una sociedad mucho más idílica, viéndola como un terreno de cooperación y de ayuda mutua. Posiblemente la posición del niño dentro de la sociedad, como un ser dependiente, que generalmente es ayudado y querido por los adultos, y sin tener que sufrir, por regla general, los ataques de otros, facilita esta idea.

En primer lugar, la sociedad que concibe el niño parece que se ve como un orden completamente racional (igual, por otra parte, que el mundo físico), en el que cada cosa está situada en el sitio que le corresponde y la realidad sirve para satisfacer las necesidades del hombre. La sociedad es un lugar sin conflictos en el que todos cooperan con todos y cada elemento funciona perfectamente. Los conflictos están ausentes y la injusticia no existe, probablemente porque la injusticia se ve como algo irracional e innecesario. En todo caso, si se comprueba su existencia no puede explicarse, ni se encuentran soluciones viables, y tiene que tratarse de un fenómeno claramente excepcional.

Naturalmente los niños están también en contacto con situaciones en las que las cosas no parecen producirse así. Pueden percibir la pobreza, la desigualdad, la enfermedad o el dolor. Todo esto no encaja bien en el esquema anterior y por ello tienden a verlo como situaciones anómalas y excepcionales, que sólo son alteraciones poco frecuentes de la norma general. Hay individuos que no cumplen con sus obligaciones porque son malos, es decir, por razones personales intrínsecas. Esto se relaciona con otras características del pensamiento social infantil que mencionaremos a continuación.

Los individuos, por su parte, se esfuerzan por comportarse lo mejor posible, ayudando a los demás y movidos siempre por intereses altruistas. Al mismo tiempo, son personas que conocen muy bien lo que tienen que hacer y que saben cómo se hacen las cosas. Los adultos tienen siempre el saber necesario, y el conocimiento ocupa un lugar muy importante en la valoración del niño. Los políticos, los administradores, los técnicos son personas que saben y que hacen su tarea bien. Los políticos, los que desempeñan funciones sociales prominentes, son personas que saben mucho y que han llegado a esos puestos tras largos años de estudio. En conjunto, la noción de saber ocupa un lugar privilegiado en la comprensión infantil de la realidad social. Saber y autoridad se identifican, y las personas que detentan el poder son las que tienen autoridad; la autoridad se relaciona con el conocimiento: los que más mandan son los que más saben.

En segundo lugar, los niños entienden el orden social como si estuviera regido por preferencias personales y no son capaces de ver actuaciones impersonales o de carácter propiamente social institucionalizado. Éste es un aspecto que ha sido señalado por Furth (1980).

En tercer lugar la visión que el niño tiene de la sociedad es como una imagen en blanco y negro, con pocos matices. Las personas buenas son muy buenas y las malas muy malas, los ricos son muy ricos y los pobres muy pobres. Las posiciones intermedias son más difíciles de entender y los niños no gustan mucho de las sutilezas. Ésta es la imagen que presentan los cuentos infantiles que por ello mismo les resultan tan atractivos. 
En cuarto lugar, la sociedad del niño es una sociedad de la abundancia en la que la escasez no tiene lugar. Las cosas son abundantes y siempre podemos encontrar lo que necesitamos. En la tienda hay tantos vasos como queramos y si los bolígrafos se agotan, pronto habrá más. El dinero lo podemos obtener en el banco (o incluso a través del cambio en la tienda) y cuando se nos acaba vamos por más. Los pobres son muchas veces los que no saben ir al banco por dinero. Esa abundancia es naturalmente relativa a la situación del propio niño, pero en un orden racional que está hecho para favorecer el bienestar de los humanos las cosas que se necesitan se pueden obtener. El dinero, los alimentos o bienes necesarios para la vida están disponibles cuando se necesitan. Como al mismo tiempo, las cosas están regidas por unos propios pocos principios es necesario pagar por todo y un ejemplo de ello es la creencia en que el trabajo se compra (Delval, 1994).

En quinto lugar, al concebir un mundo regido por unos pocos principios simples y de aplicación general, el niño no entiende los conflictos sociales como motivados por la presencia de intereses contrapuestos. Los intereses de cada uno deben coincidir y deben coincidir también con el interés general. Por ello no pueden existir los conflictos y si éstos se producen sólo pueden deberse o a la ignorancia o a la maldad. En el caso de los derechos, si alguien viola un derecho será debido a que no se ha dado cuenta de lo que está haciendo y la manera de corregir la situación es hacérselo ver. Por eso la figura de un mediador es importante porque permite que se hable con esas personas y que se den cuenta de su error, su función es la de convencerlos.

Por las mismas razones, el compromiso es algo que está ausente de las concepciones infantiles. La idea de compromiso en el terreno del desarrollo social, y en concreto político, que ha sido señalada por Furth y McConville (1981), supone la aceptación de que existen diferentes maneras de concebir la realidad o de actuar que son todas razonables o pueden sostenerse por lo que, cuando existen intereses contrapuestos, debe intentar llegarse a un acuerdo en el que los defensores de las diferentes posiciones ceden una parte de sus pretensiones para lograr la posibilidad de llegar a un acuerdo. Por ello la idea de compromiso no resulta precisa en las explicaciones infantiles y es un descubrimiento de la adolescencia tardía. Esto puede dar lugar a entender la figura de un mediador muy distinto del que se concedía anteriormente. El nuevo mediador no tiene como misión convencer sino lograr una cesión de parte de los derechos entre los implicados en el conflicto.

En sexto lugar, el niño concibe difícilmente que el orden social pueda alterarse. Es como es y lo seguirá siendo, como consecuencia de que es el mejor. Esto lo manifiestan los niños en sus respuestas sobre múltiples problemas sociales. Si no hubiera maestros no se podría aprender (Furth, 1980, p. 39). Si no hubiera tiendas, no podríamos comprar y nos moriríamos. Si no hubiera dinero, no podríamos obtener lo necesario para la vida. Si no hubiera jefes, sería el desorden total y lo mismo pasaría con la ausencia de leyes. Si cambiaran esas condiciones, el orden social se alteraría profundamente o se destruiría totalmente. No se pueden imaginar reajustes en el sistema ni formas alternativas de funcionamiento.

Resulta sorprendente ese mundo del niño tan racional y tan ordenado en el que, sin embargo, unos elementos no pueden relacionarse con otros. Pero todo este mundo de bondad y de racionalidad se empieza a desmoronar en el momento de la adolescencia, cuando la realidad se comienza a entender de manera mucho más exacta y, al mismo tiempo, el individuo empieza a comprobar su impotencia para cambiar el mundo irracional que empieza a descubrir y que es tan contrario a todo lo que le han enseñado como niño durante los largos 
años pasados en la escuela. La realidad social entra en contradicción con todos los valores que se han recibido y con todas las enseñanzas morales que se le han transmitido. El origen de muchos problemas sociales actuales, $\mathrm{y}$ también de otras épocas, se encuentra posiblemente en ese choque, en ese conflicto, en esa desilusión, en esa frustración que se produce en la adolescencia y que puede tener consecuencias de muy largo alcance.

\section{REFERENCIAS BIBLIOGRÁFICAS}

1. Barrett, M. y Buchanan-Barrow, E. (Eds) (2005). Children's understanding of society. Hove: Psychology Press.

2. Berger, P.L. y Luckmann, T.(1966). The social construction of reality. Nueva York: Doubleday. Trad. cast. de Silvia Zulueta: La construcción social de la realidad. Buenos Aires: Amorrortu, 1968.

3. Berti, A. E. y Bombi, A.S.(1981/88). Il mondo economico nel bambino. Firenze: La Nuova Italia. Trad. inglesa, revisada y ampliada, de G. Duveen: The child's construction of economics. Cambridge: Cambridge University Press, 1988.

4. Brooks-Gunn, J. y Lewis, M. (1978). Early social Knowledge: the development of knowledge about others. En McGurk, H. (Ed.) (1978) Issues in childhood social development. Londres: Methuen.

5. Danziger, K. (1958). Children's earliest conceptions of economic relationships (Australia). Journal of Social Psychology, 47, 231-240.

6. Delval, J. (1989). La representación infantil del mundo social. En I. Enesco, E. Turiel y J. Linaza (Eds) El mundo social en la mente infantil. Madrid: Alianza.

7. Delval, J. (1991). Notas sobre la construcción del conocimiento social. En I. Alonso Hinojal, J. Carabaña, M. Fernández Enguita y M. Subirats (Comps.) Sociedad, cultura y educación: Homenaje a la memoria de Carlos Lerena Alesón. Madrid: CIDE y Universidad Complutense, pp. 191-208.

8. Delval, J. (1994). Stages in the child's construction of social knowledge. En M. Carretero y J.F. Voss (Eds.) Cognitive and instructional processes in history and the social sciences. Hillsdale: LEA.

9. Delval, J. (1995). Algunas reflexiones sobre los derechos de los niños. Infancia y sociedad, $\mathrm{N}^{\mathrm{o}}$ 27-28., pp.

10. Delval, J. (2000). Sobre la naturaleza de los fenómenos sociales. En K. Korta y F. García Murga (Comps.) Palabras. Víctor Sánchez de Zavala in memoriam. Bilbao: Servicio Editorial de la UPV-EHU, pp. 95-122.

11. Delval, J. (2001). Descubrir el pensamiento de los niños. Introducción a la práctica del método clinico. Barcelona: Paidós. Traducción al portugués por Fátima Murad: Introdução à prática do método clínico: Descobrindo o pensamento das crianças. Porto Alegre: Artmed, 2002.

12. Delval, J. (2002). Vigotsky, Piaget: a formação do conhecimento e a cultura. Educação e Realidade.(Porto Alegre), v. 26, N $^{\circ}$ 2, pp. 89-126, julio/diciembre 2001. [Figura como 2001]. 
13. Delval, J. y del Barrio, C. (1992). Las ideas de los niños acerca de la guerra y la paz. En: F. Moreno y F. Jiménez Burillo (Coords.) La guerra: Realidad y alternativas. Madrid: Editorial Complutense, pp. 165-174.

14. Delval, J. y Barrio, C. del (2002). A compreensão infantil das guerras e a educação para a paz. Pátio (Porto Alegre), N²1, mayo-julio 2002, pp. 48-51.

15. Delval, J., del Barrio, C. y Echeita, G. (1981). El conocimiento de los niños de su propio país. Cuadernos de Pedagogía, 75, 33-36. Reproducido en: J. Delval, La psicología en la escuela. Madrid: Visor, 1986, pp. 93-99.

16. Delval, J., Barrio, C. del y Espinosa, M. A. (en preparación) Los derechos de los niños vistos por los propios niños.

17. Delval, J. y Echeita, G. (1991). La comprensión en el niño del mecanismo de intercambio económico y el problema de la ganancia. Infancia y Aprendizaje, 54, 71-108.

18. Delval, J. y Enesco, I. (1994). Moral, desarrollo y educación. Madrid: Anaya-Alauda.

19. Delval, J., Enesco, I. y Navarro, A. (1994). La construcción del conocimiento económico. En M.J. Rodrigo (Comp.) Contexto y desarrollo social. Madrid: Síntesis, pp. 345-383.

20. Delval, J. y Denegri, M. (2002). Concepciones evolutivas acerca de la fabricación del dinero. I. Los niveles de comprensión. Investigación en la escuela, 48, 39-54..

21. Delval, J., Díaz-Barriga, F., Hinojosa, M. L. y Daza, D. (1992). Experiencia y conocimiento social: Un estudio preliminar sobre las ideas de trabajo y ganancia en niños trabajadores mexicanos. Manuscrito no publicado. Universidad Autónoma de Madrid, Departamento de Psicología Evolutiva y de la Educación.

22. Delval, J., Kohen, R. y Barrio, A. (en preparación) Los niños y el euro: La comprensión del proceso de unificación y sustitución de una moneda.

23. Delval, J. y Padilla, M. L. (1999). El desarrollo del conocimiento sobre la sociedad. En F. López, I. Echebarría, M. J. Fuentes, y M. J. Ortiz (Eds.) El desarrollo afectivo y social. Madrid: Pirámide, 1999, pp. 125-150.

24. Delval, J. Soto, P., Fernández, T., Gil Carnicero, P. et al, (1971). Estructura y enlace de los conocimientos científicos: epistemología genética. Ciencias Sociales: Las nociones de economía y poder. Memoria de investigación. Madrid: Instituto de Ciencias de la Educación de la Universidad Autónoma de Madrid.

25. Denegri, M. (1995). El desarrollo de las ideas acerca de la emisión monetaria en niños y adolescentes: Un estudio exploratorio. Tarbiya, $\mathrm{N}^{\circ}$ 9, 47-60.

26. Denegri, M. y Delval, J. (2002). Concepciones evolutivas acerca de la fabricación del dinero. II. Los tipos de respuestas. Investigación en la escuela, 48, 55-70.

27. Eisenberg, N. (1989) The development of prosocial values. En N. Eisenberg, J. Reykowski y E. Staub (Eds.) Social and moral values: Individual and societal perspectives. Hillsdale: Erlbaum.

28. Enesco, I., Delval, J. Navarro, A., Villuendas, D., Sierra, P. y Peñaranda, A. (1995). La comprensión de la organización social en niños y adolescentes. Madrid: Ministerio de Educación y Ciencia (CIDE). 
29. Franklin, B. (1995). The case for children rights. En B. Franklin (Ed.) The handbook of children's rights. Londres: Routledge.

30. Furnham, A. y Stacey, B. (1991). Young people's understanding of society. Londres: Routledge.

31. Furth, H.G. (1980) The world of grown-ups. Children's conceptions of society. Nueva York: Elsevier North Holland.

32. Furth, H.G. y McConville, K. (1981). Adolescent understanding of compromise in political and social arenas. Merrill-Palmer Quarterly, 27, 413-427.

33. Heller, D. (1986). The children's God. Chicago: University of Chicago Press.

34. Jahoda, G. (1979). The construction of economic reality by some Glaswegian children. European Journal of Social Psychology, 9, 115-127.

35. Jahoda, G. (1981). The development of thinking about economic institutions: the bank. Cahiers de Psychologie Cognitive, 1, 55-73.

36. Jahoda, G. (1983). European 'lag' in the development of an economic concept: A study in Zimbabwe. British Journal of Developmental Psychology, 1, 113-120.

37. Jahoda, G. (1984). The development of thinking about socio-economic systems. En Tajfel, H. (Ed.) The social dimension, vol. I, Cambridge: Cambridge University Press.

38. López, F., Torres, B., Fuertes, J., Sánchez, J. M. y Merino, J. (1995). Necesidades de la infancia y protección infantil, 2. Madrid: Ministerio de Asuntos Sociales.

39. Murià, I. (1995). La noción de religión en los niños y adolescentes: Estudio comparativo entre mexicanos y españoles. Tesis doctoral no publicada. Madrid: Universidad Autónoma.

40. Moscovici, S. (1976). La psychanalyse, son image et son public. París: P.U.F., $1^{\text {a }}$ ed. 1961.

41. ONU (1989) Convención sobre los derechos del niño y la niña. Madrid: Comunidad de Madrid: 1983.

42. Piaget, J. (1924). Le jugement et le raisonnement chez l'enfant. Neuchâtel: Delachaux y Niestlé. Trad. cast. Buenos Aires: Guadalupe, 1972.

43. Piaget, J. (1926). La répresentation du monde chez l'enfant. París: Alcan. Trad. cast. La representación del mundo en el niño. Madrid: Morata, 1973.

44. Piaget, J. (1932). Le jugement moral chez l'enfant. París: Alcan, 4. ed., P.U.F., 1969. Trad. cast.: El juicio moral en el niño. Madrid: Beltrán, 1935. Nueva traducción de Nuria Vidal: El criterio moral en el niño. Barcelona: Martínez Roca, 1984.

45. Piaget, J. y Weil, A.M. (1951). Le development, chez l'enfant, de l'idée de patrie et des relations avec l'étranger. Bulletin International des Sciences Sociales, 3, 605-621. Trad. cast. en J. Delval, Lecturas de psicología del niño, T. II, Madrid: Alianza, 1978, pp. 325-342.

46. Searle, J. R. (1995). The construction of social reality. Nueva York: Free Press. Trad. cast. de A. Domenech, La construcción de la realidad social. Barcelona: Paidós, 1997. 
47. Shantz, C.U. (1982). Children's understanding of social rules and the social context. En: Serafica, F.C. (Ed.) Social cognitive development in context. Nueva York: The Guilford Press.

48. Strauss, A.L. (1952). The development and transformation of monetary meanings in the child. American Sociological Review, 27, 275-284.

49. Strauss, A.L. (1954) The development of conceptions of rules in children. Child Development, 25, 192-208.

50. Turiel, E. (1979). Distinct conceptual and developmental domains: Social Convention and Morality. Nebraska Symposium on Motivation, 1977 (Vol. 25). Lincoln: University of Nebraska Press. 